\title{
Performance Analysis of Slotted Carrier Sense IEEE 802.15.4 Medium Access Layer
}

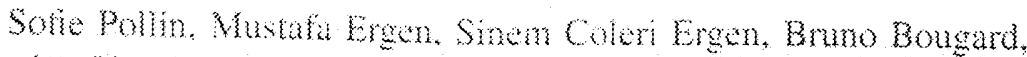

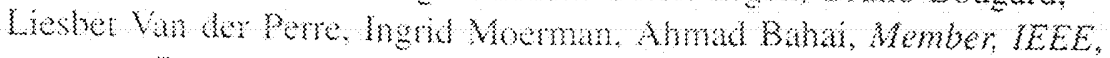

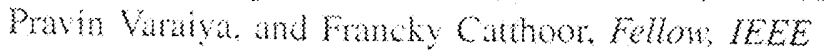

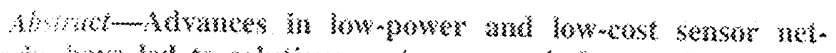

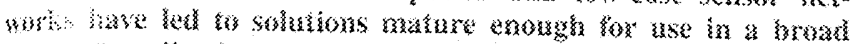

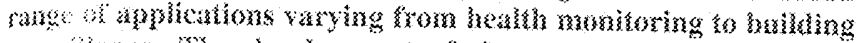

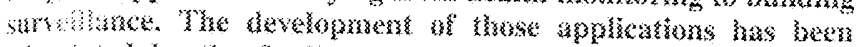

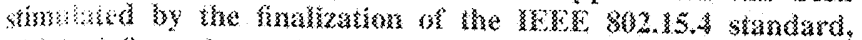

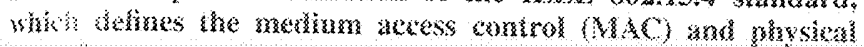

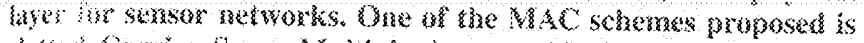

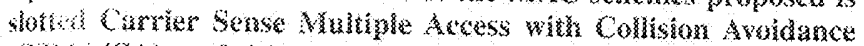

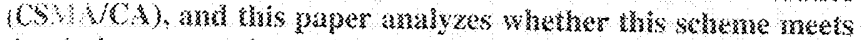

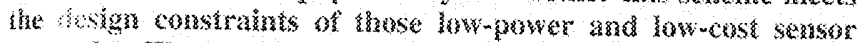

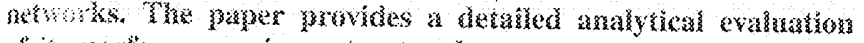

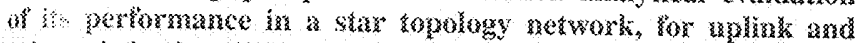

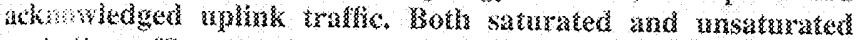

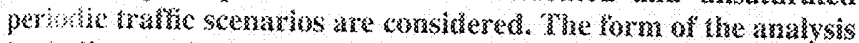

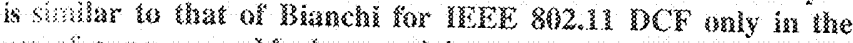

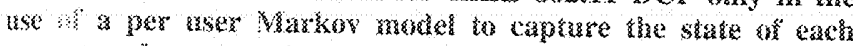

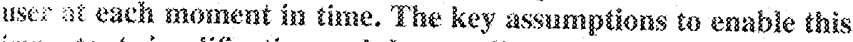

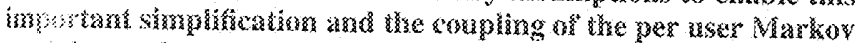

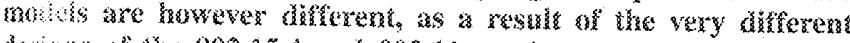

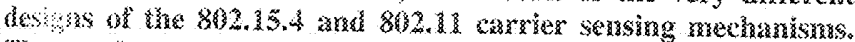
The wertormance predicter by the andytical model is very

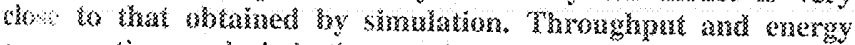

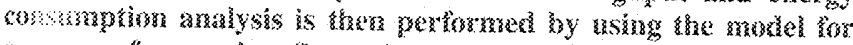

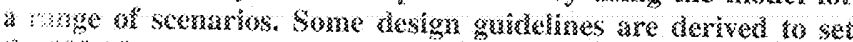

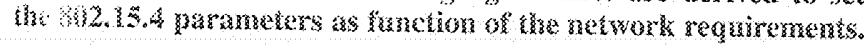

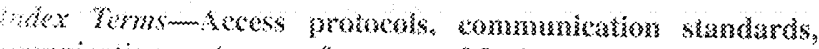

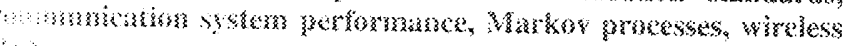
:

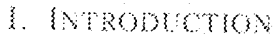

W

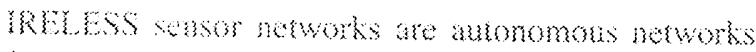

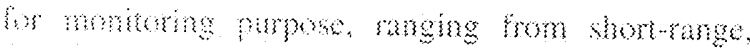

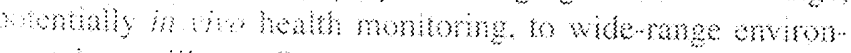

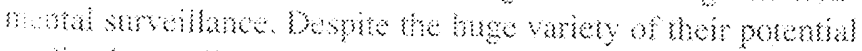

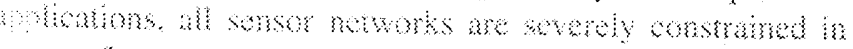

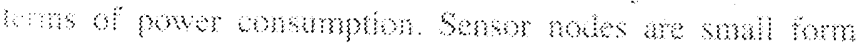

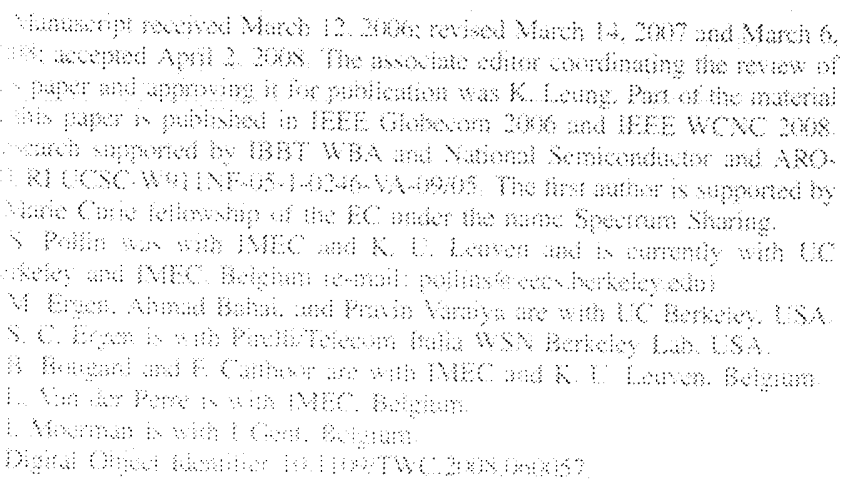

factor batery powered devices and size conctraings limit the battry capacity. In most cases, the density of the network or the vaste enviromment where they are deployed pronibits a periodic replacement of the batueries. This makes energy difciency a very importan design requirement for those networks.

In a general way, the ask of a sensor newwok consists of measuring a variable through the sensors. evenually

(pre-)processing this intormation, and if opportune, transmitting the data to a data sink. It has been shown in various design cases 11$]$ that some of the most power hungry tasks of sensors are related to the communication: not only transmission and receive power, but the power needed while wating (idle) and scanning the channel can be significant.

To address these requirements, the MEEE 802.15 .4 standard which specifes the network's medium access control (MAC) and physical (PHY) layer, has been developed $[2],\{3\},[4]$. $n$ IEEE $802 .\{5.4$ sensor networks a central controller, called the PAN (personal area network) coondinator, builds the network in its persomal operaing space. The standard supports fimee newwoking topologies relevant to sensor neworking applica

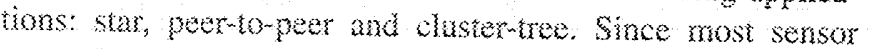
network applications involve monitorng lasks and reporking bowards a central sink, and sinwe the focus of thes payer is on the 802.15 .4. nedum access comman analysis, we bous on

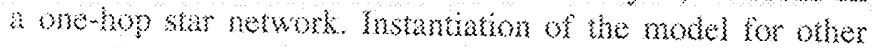
yges of nekworks is abo yosible.

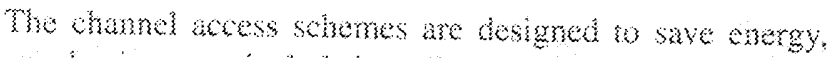

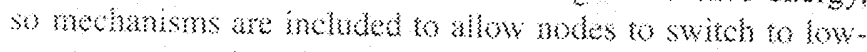

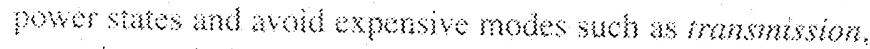

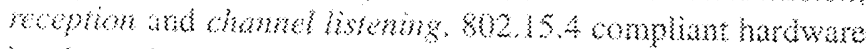

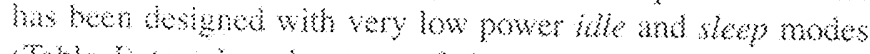

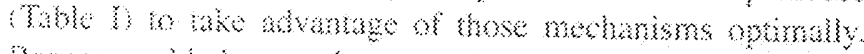

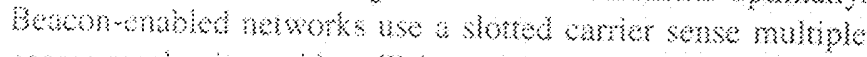

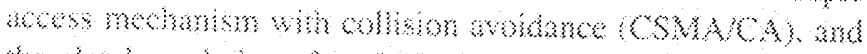

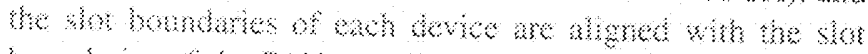

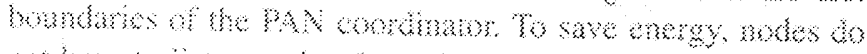

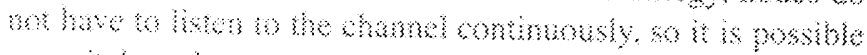

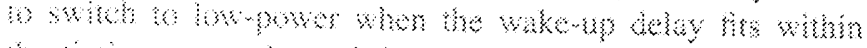

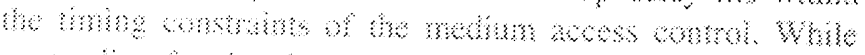

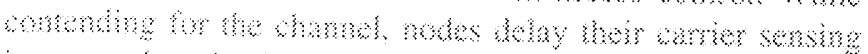

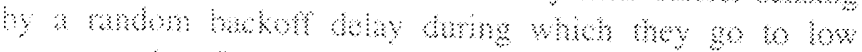

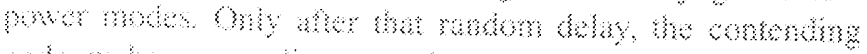

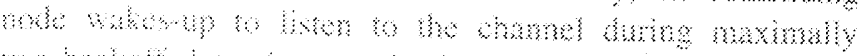

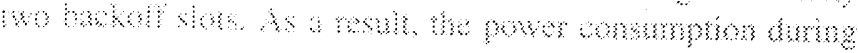




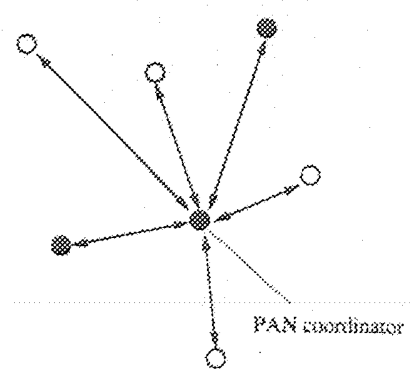

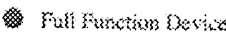

O Xeducat mankon bexice

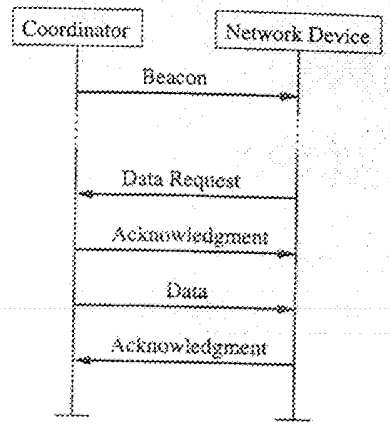

Disenting

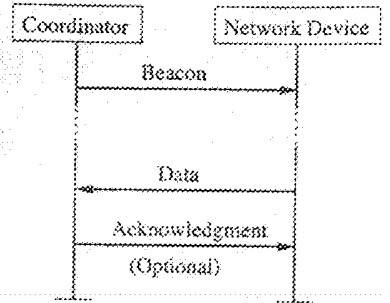

Goyizk

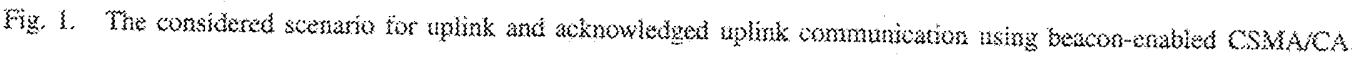

TABRE

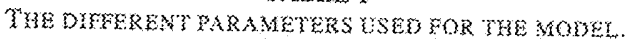

\begin{tabular}{|c|c|c|}
\hline 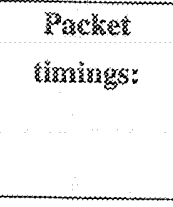 & 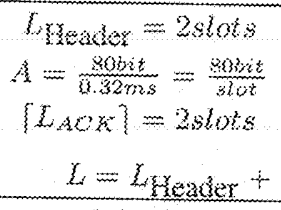 & 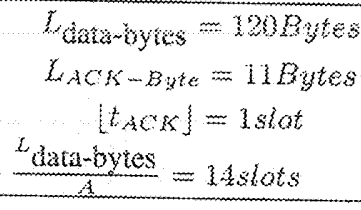 \\
\hline $\begin{array}{l}\text { Variable } \\
\text { gyaxaraters: }\end{array}$ & 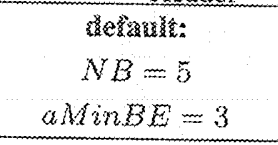 & $\begin{array}{c}\text { raxge: } \\
{[0.5]} \\
{[0.3\}}\end{array}$ \\
\hline X) & $a M / a x B E=5$ & $C W=2$ \\
\hline $\begin{array}{l}\text { PSWer } \\
\text { states: }\end{array}$ & $\begin{array}{c}R x=40 \mathrm{~mW} \\
R x=30 \mathrm{~mW} \\
S l e \varepsilon p=0.16 \mu W\end{array}$ & $\begin{array}{l}C C A=40 \mathrm{~mW} \\
1 \mathrm{dle}=0.8 \mathrm{~mW}\end{array}$ \\
\hline
\end{tabular}

chamel histening is mimimized. To receive data, pending data reception is announced through the beacon, and the data is sent by the central coordinator only after receiving the data request message that moms the coordixator that the device

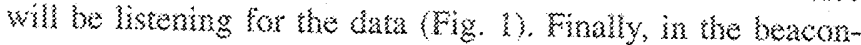

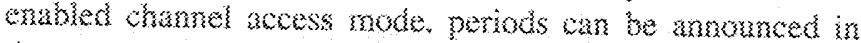

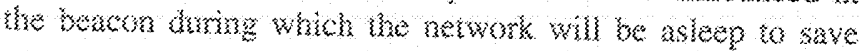

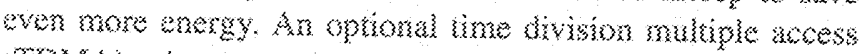

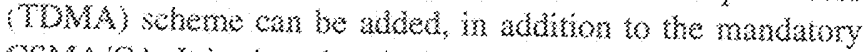

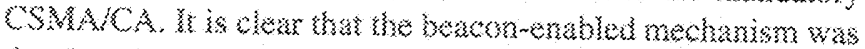

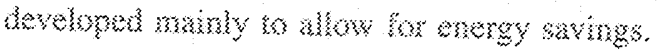

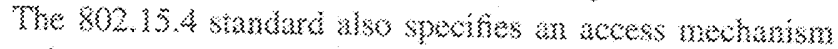

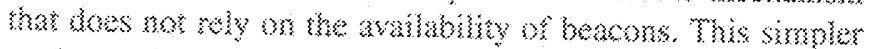

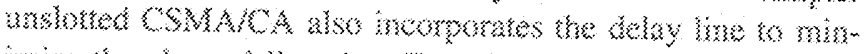

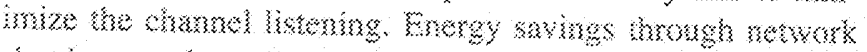

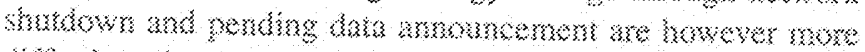

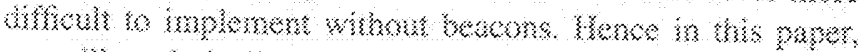

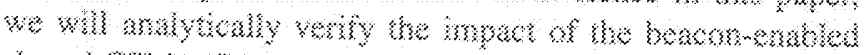

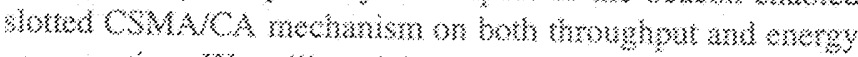

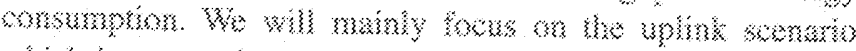

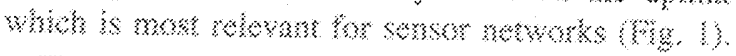

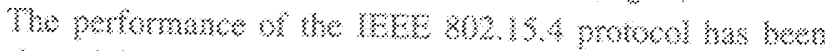

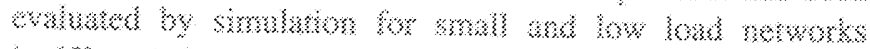

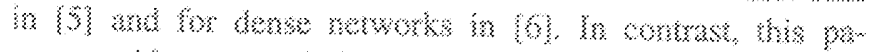

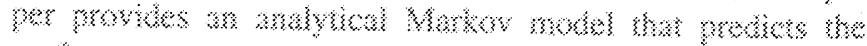

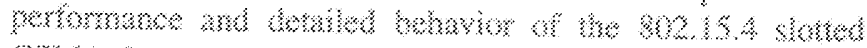

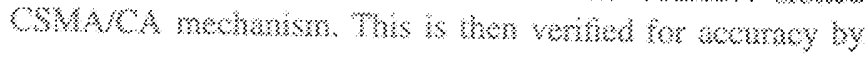

detaited comparison to simulation. The model incorporates dezails of the exponential delay lines and double Clexr Channe? Assessment (CCA). The form of the analysis is similar to that of Bianchi for IEEE 802.11 DCF [10], [11] only in the use of a per user Markov model to capture the state of each user at each moment in tyme. The assumptions to enable this importan simplification and the coupling of the per user models are however different, as a result of the very differem design of the 802.11 carrier sensing mechanisn where nodes monitor the channel continuously and are hence continuously aware of the channel state. This small difference results however in a key difference in the main approximation assumptions: Each device's carrier sensing probability, rather than its packet sending probability, is assumed independent. Also, unlike in 802.11 , the slot duration is fxed since the channel is not constantly monitored by the stations and only a fixed slot duration model can keep the system synchronized. Finally, the fixed duration two-shot clear channel assessment leads to menory in the conwhing of the per user individul Markov chams. The andyetical model for IEEE 802.35 .4 developed in 17. (8) Wals to match the simndation results. since they used the same Markov formulation and assunwowons as Gianchi in 100 tor 802.3 .

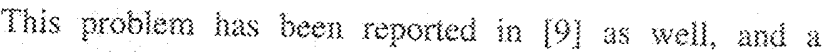

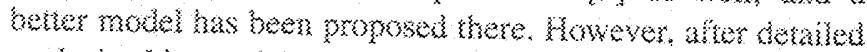

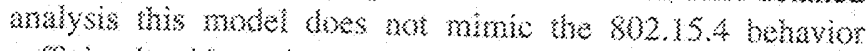

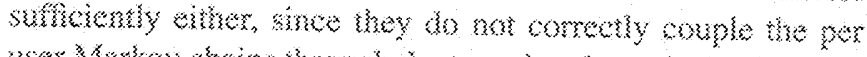

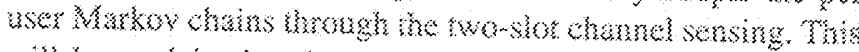

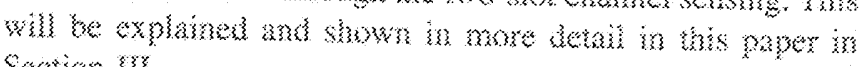
Section पy

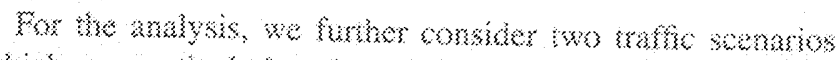

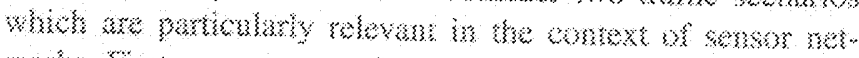

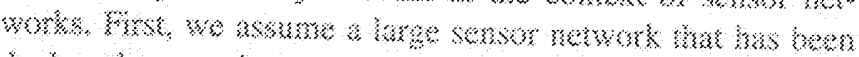

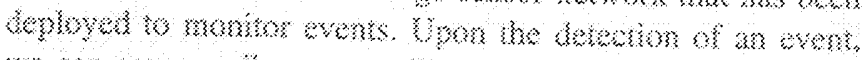

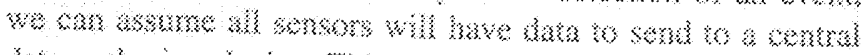

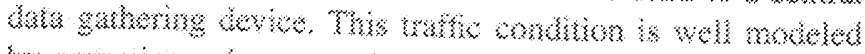

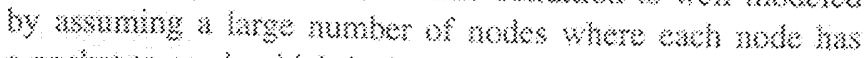

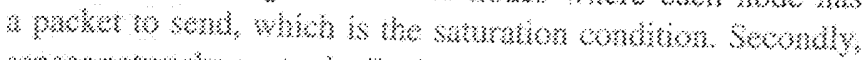

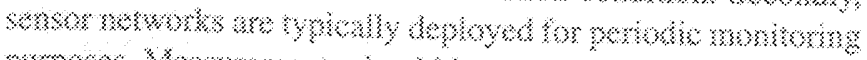

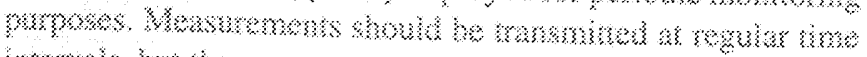

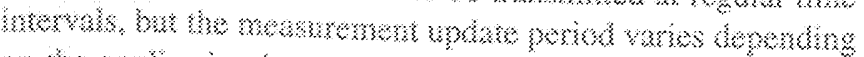

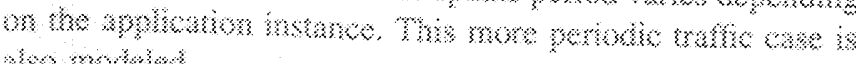
ale moled

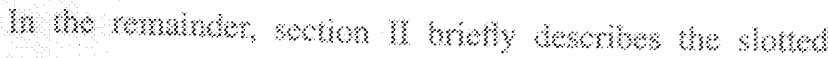




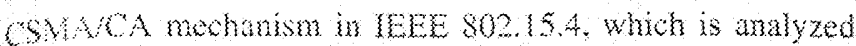

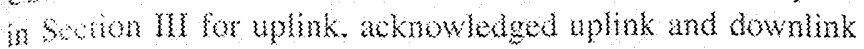

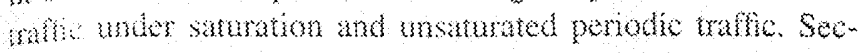

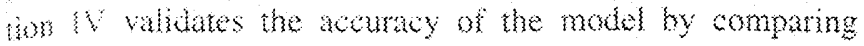
tase matical predictons and simulation resuls. Secton

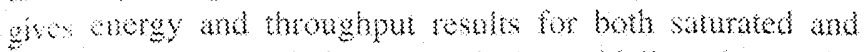

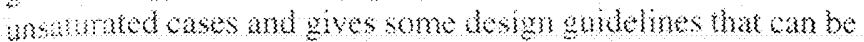

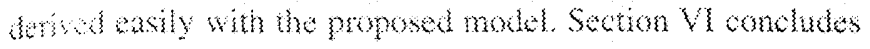
as me

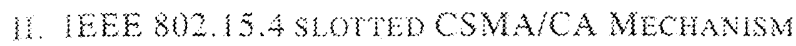

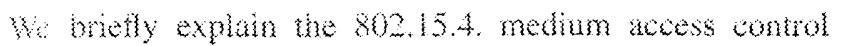

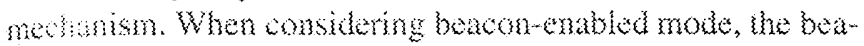

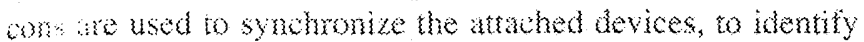

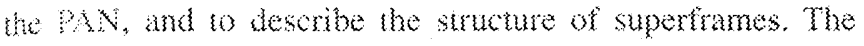
smm hames are boumbd by nework bexcons and dived into 16 caislly sized slots. The bean frame is sent in the forat sut of ach superframe.

Ho superame cal have an active and an inactive portion. Darieg the inactive portion the coordinator does not interact wite is PAN and may ener a low-power mode. The active pormen consists of a contention aceess pertod (CAP) and is contention free periol $(\mathrm{CH})$. A device that wishes to commuicate during the CAP competes with other devices ustr: a shoted CSMAKCA mechanism. On the other hand, the Ch conains guaranted time slots (GTSS). The GTSs appear at the end of the active portion sarting at a slot boundary immediately following the CAP.

Whe shoted CSMA/CA channe access mechanism, the bukof sot boudaries of every devine in the PAN are aligned why the supertane slot boundaries of the PAN coordinator.

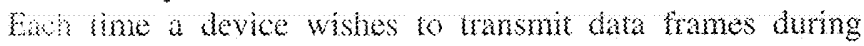
the AP, it must beate the bondiary of the nox slot perod. Moover, before accesing the channe, a ronom number of

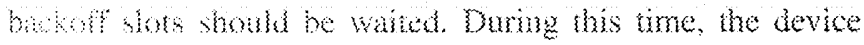

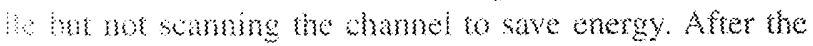

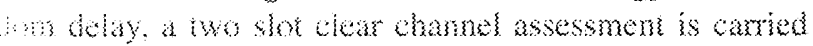

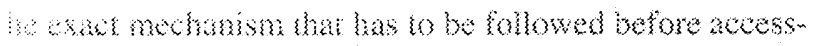

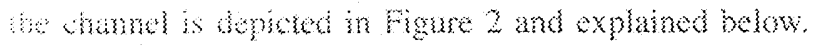

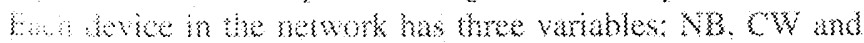

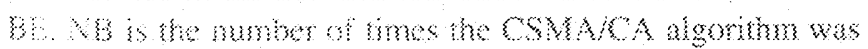

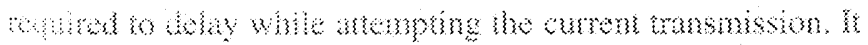

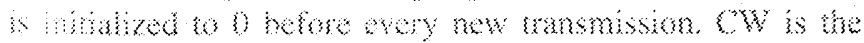

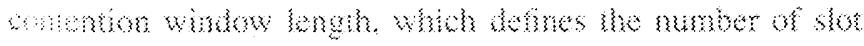

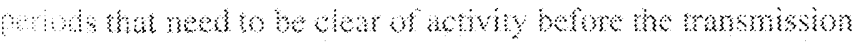

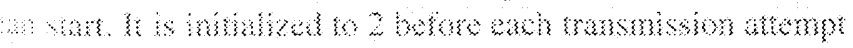

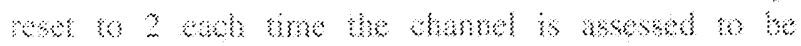

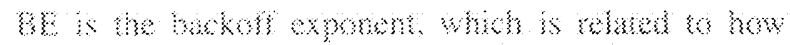

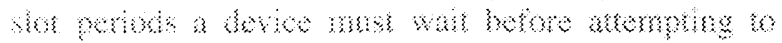

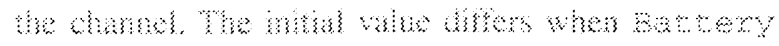

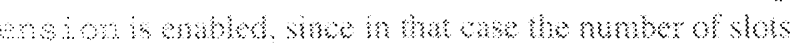

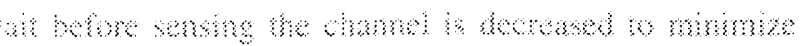

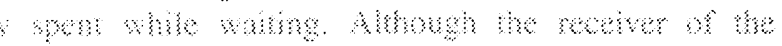

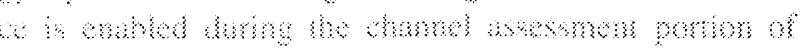

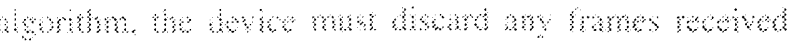
काओ

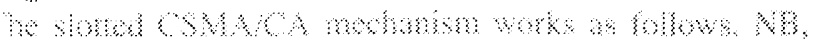

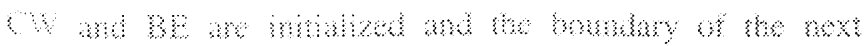

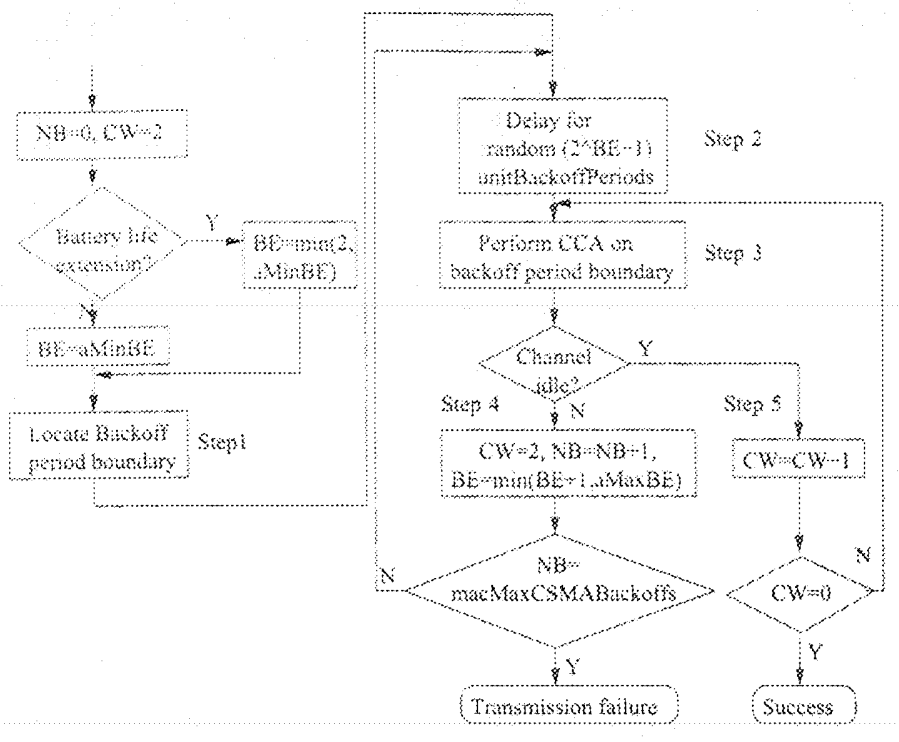

Fig, 2. Backof mechanism for 802.15. CSMA.

slot period is located (stepl). The MAC layer delays for a randon number of complete slot pertods in the range 0 to $2^{k E}-1(\operatorname{step} 2)$ and then requests PKY to pertom a CCA (clear channel assessmen) (step 3). The MAC sublayer then proceds provided that the remaining CSMA/CA algorithm steps-rume transmission, and any acknowledgmentm can be completed betore the end of the CAP. Th the MAC sublayer cannot proceed, it must wait until the start of the CAP in the next superframe and then repeat the evaluation.

to the channel is assessed to be busy (step 4), the MAC sublayer increments both $\mathrm{NB}$ and $\mathrm{B}$ E by one, enswing that BE is not more than aMaxbE, and CW is reset to 2 , The value of NB is less than or equal to mackax CSMABackoffs. the CSMAKC must return to step 2, else the CSMA/CA must teminate with a Cumal-Access falure suatus. The

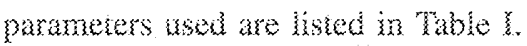

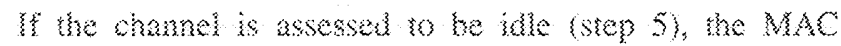

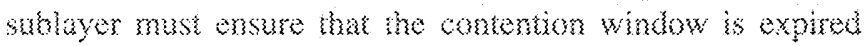

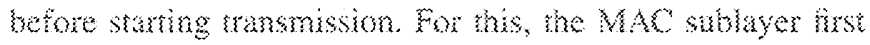

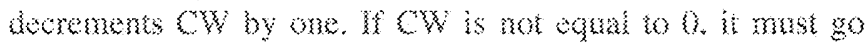

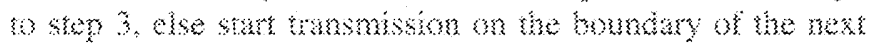
suc perat.

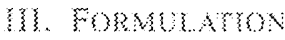

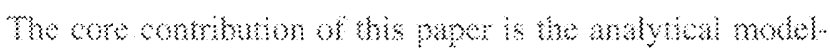
mo of

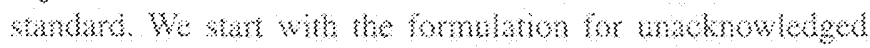

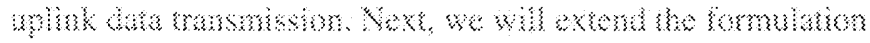

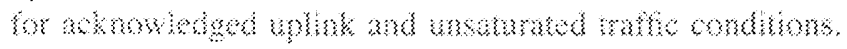

\section{A. Think shmmon}

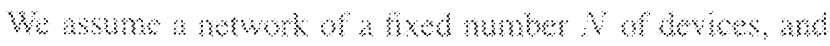

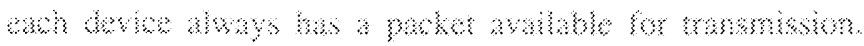

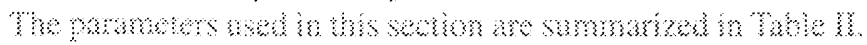

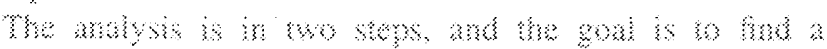

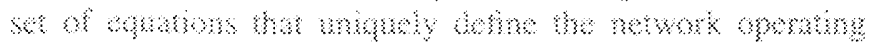

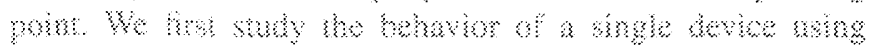




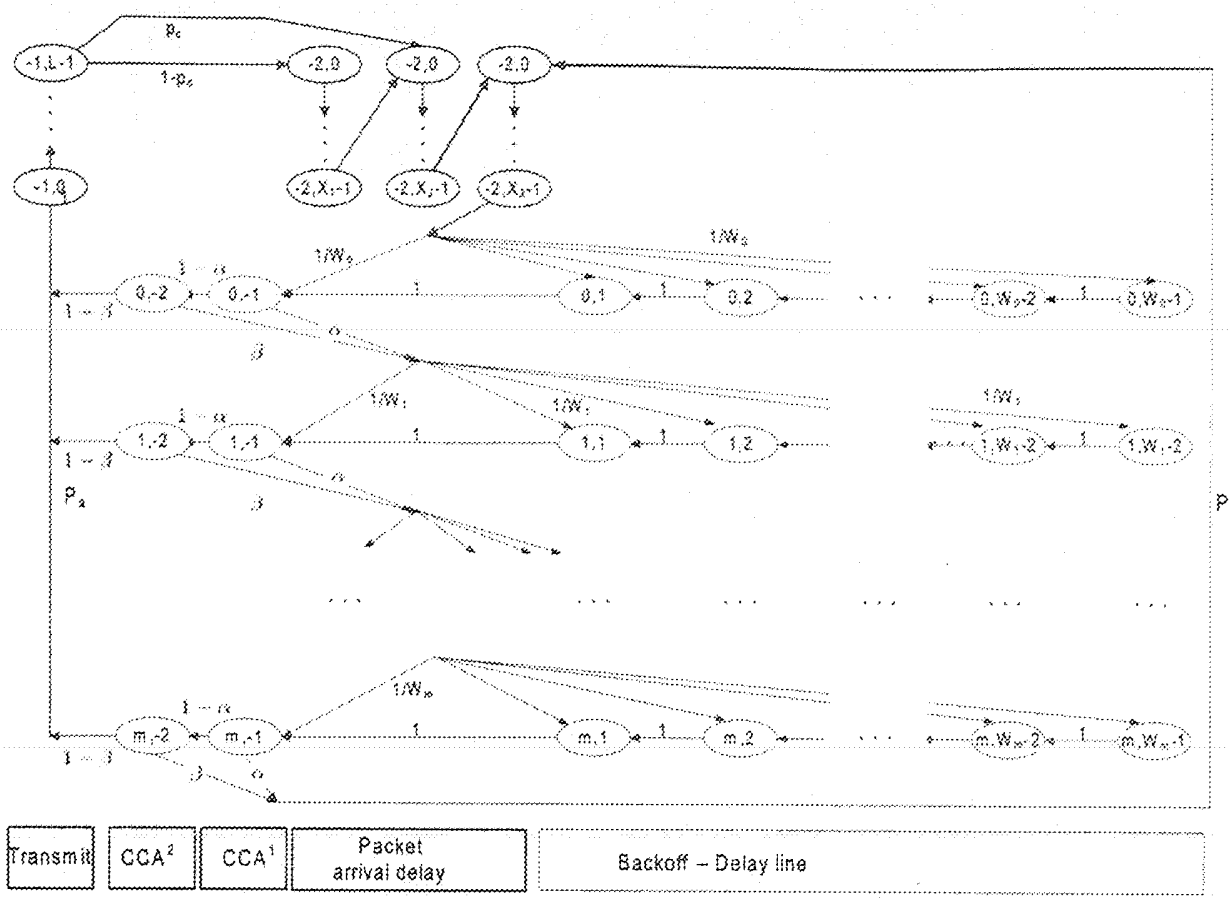

Fig. 3. Markov Model for IEEe 802.35 .4$.

TABLE IX

THE DYFEERENT SYMAOLS USEO ROR TKE MOOE.

\begin{tabular}{|c|c|}
$\phi$ & $\begin{array}{c}\text { probability to start sensing } \\
\beta\end{array}$ \\
probability to sense busy frst tine \\
probability to sense busy second time
\end{tabular}

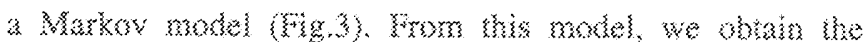

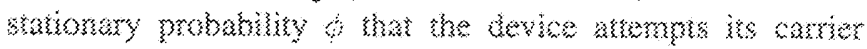

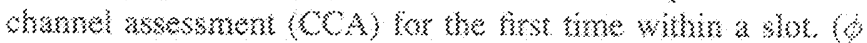

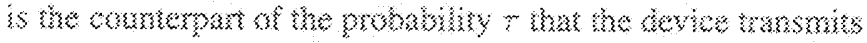

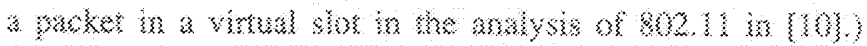

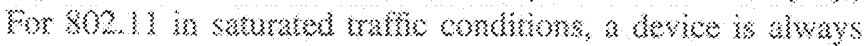

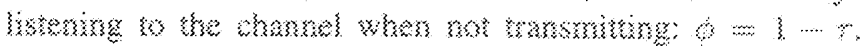

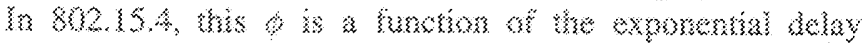

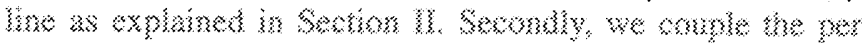

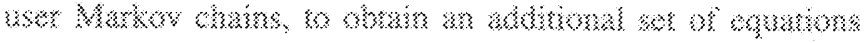

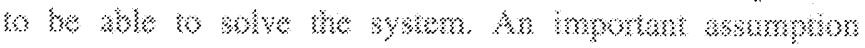

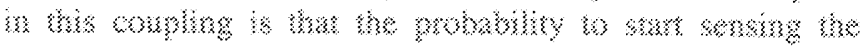

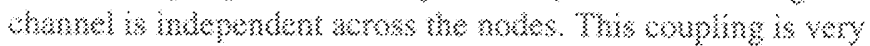

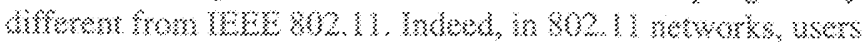

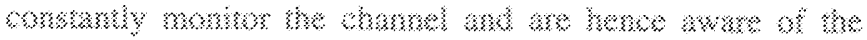

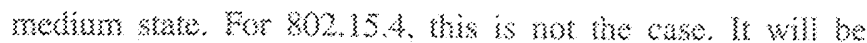

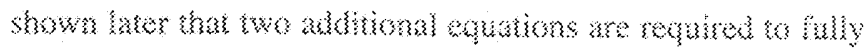

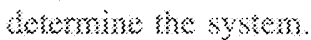

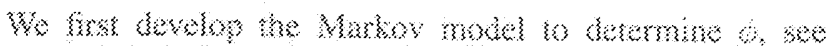

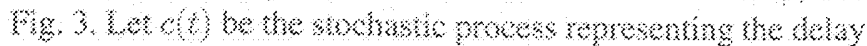

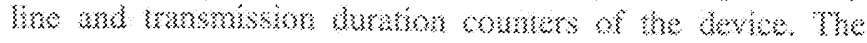

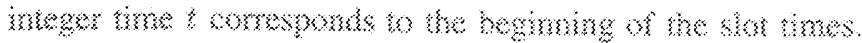

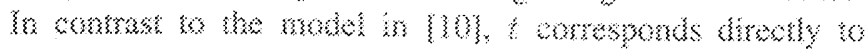

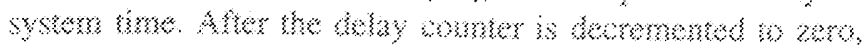

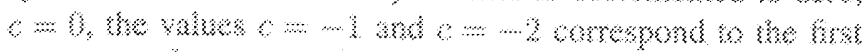

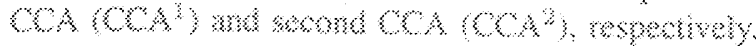

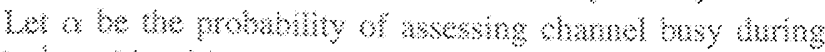

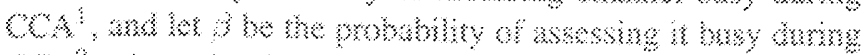

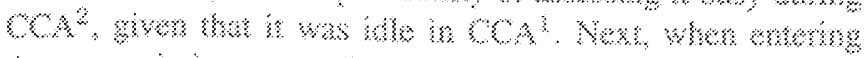

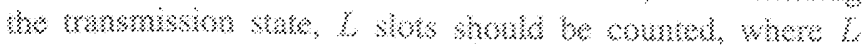


denotes the pake transmission duxaton measured in stots?

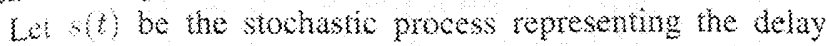

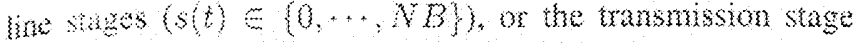

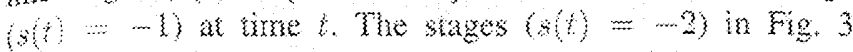

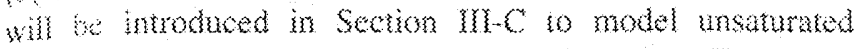

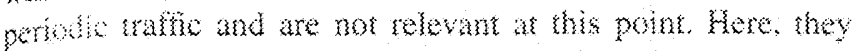

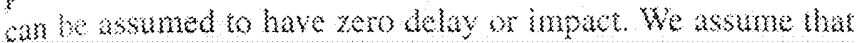
the pomobiuly to star sensing is constant and independent at other daves and of the number of remansmsions

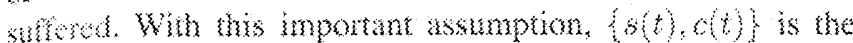

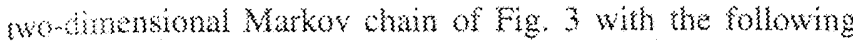
wanchon yrobablines:

$$
\begin{aligned}
& \{x, k, k, 1\}=1, k \geq 0
\end{aligned}
$$

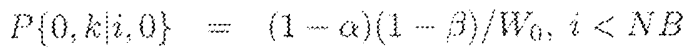

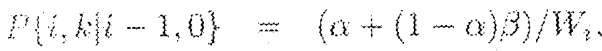

$$
\begin{aligned}
& i \leq N B, k \leq K_{i}-1 \\
& P\{0, H N B, 0\}=(1-\alpha)\left(\{-\beta) / W_{0}+P_{0} / W_{0}\right. \text {. }
\end{aligned}
$$

The delay window $W_{i}$ is initially $W_{0}=2^{4 \mathrm{~m} m} \mathrm{BE}$ and dou ble any stage unal $W_{i}=W_{\text {nax }}=2^{\text {Mar }} E E$, (aMaxBE $a M M B E) \leq i \leq N B$

Fination $I$ is the condition to decrement the delay line counter per slot. Equation 2 sates that it is only possible to ence the frst delay line from a stage that is not the last one $c<N B$ ) after sensing the chandel ble two consecutive times and hence wansmiting a packet. Equation 3 gives the wrowhility that there is a halure on both channel assessments or soming slots (CCA) and the station selects a sate in the nex: celay level. Equation 4 gives the probability of staring a now transmission atempt when leaving the last delay line, colowing a successcul or falled packet ransmission attempt. Now hat the number of transmission abemots is limiter and

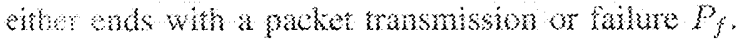

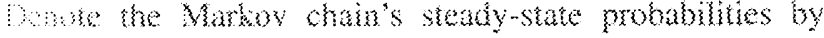

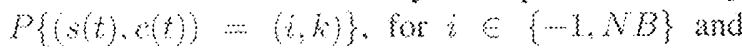

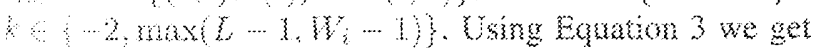

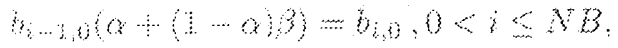

who has

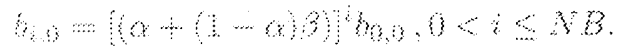

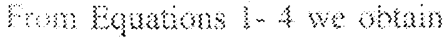

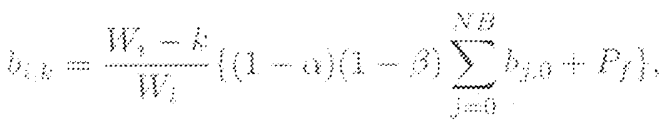

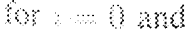

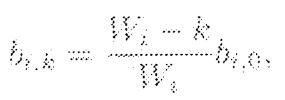

Br: $:$ o

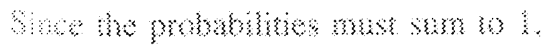

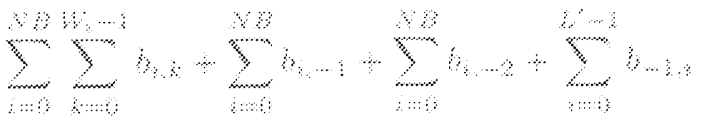

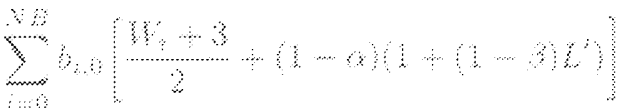

Substuting the expression for Wh this kads a the expression

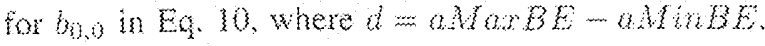

$$
\begin{aligned}
& 1 \quad=\frac{b_{0}}{2}(3+2(1-\alpha)+2(1-\alpha)(1-\beta)(b)
\end{aligned}
$$

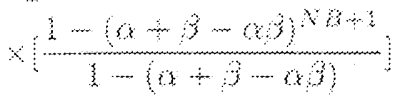

$$
\begin{aligned}
& +2^{i} Y_{0} \frac{(\alpha+\beta-\alpha \beta)^{\alpha+\alpha}-(\alpha+\beta-\alpha \beta)^{\beta}}{1-(\alpha+\beta-\alpha \beta)} \\
& \left.+W_{\{} \frac{1-(2(\alpha+\beta-\alpha \beta)}{\beta-2(\alpha+\beta-\alpha \beta)}\right\}
\end{aligned}
$$

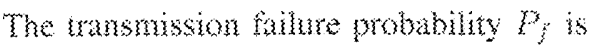

$$
P_{f}=b_{N B, 0}(\alpha \cdots \cdots+\beta)
$$

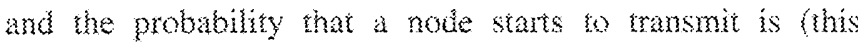
corresponds to the transmission probability $r$ in Bianchis model)

$$
r=\beta_{s}=\phi(1-\alpha)(1-\beta)
$$

in which

$$
\phi=\phi_{l}=\sum_{i=0}^{N B} b_{i, 0}
$$

We have now derived one expression for $\phi$ from the per user Markov models, By determining the interactions between users on the medium, we will now derive expressions for the remaining unknowns $\alpha$ and $\beta$.

Denote by $M(s)=-1$ the event that there is at least one transmission in the medium by another node and assume that, whont loss of generality, that the rode sensing is iN, which is denoted as $S^{i *}(\theta)=\ldots-\ldots$ is $S^{i}(s)=-1$ is the event that mode is tansminting. Then, the probability or which is

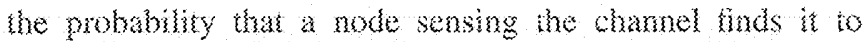

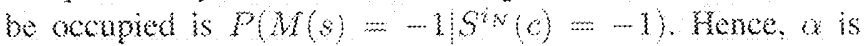
computer as kollows:

$$
\begin{aligned}
& a=p\left(M(s) \cdots \cdots\left(S^{N}(b) \cdots-1\right)\right.
\end{aligned}
$$

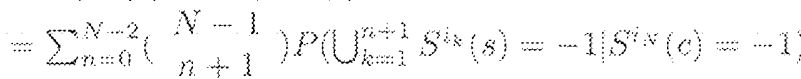

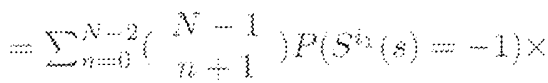

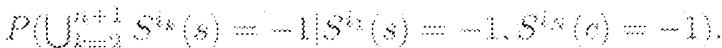

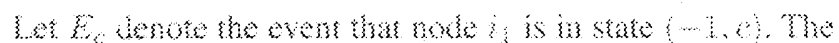

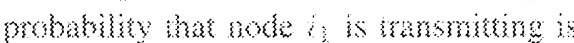

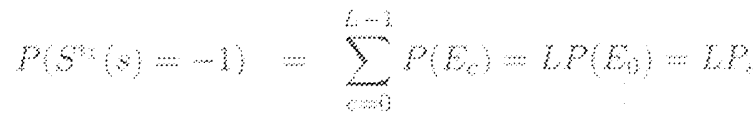

$$
\begin{aligned}
& \text {. }
\end{aligned}
$$

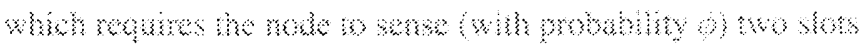

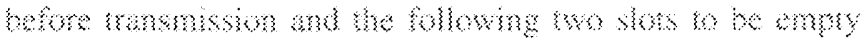

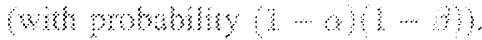

"

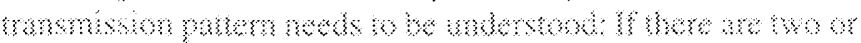

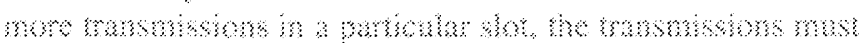

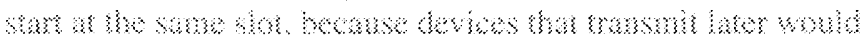

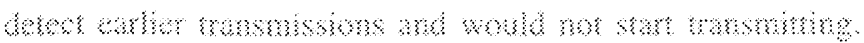

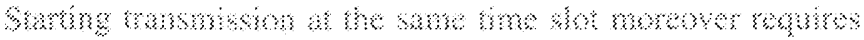




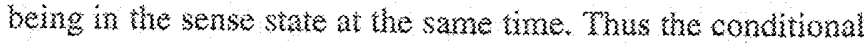
probability is hence equivalent to

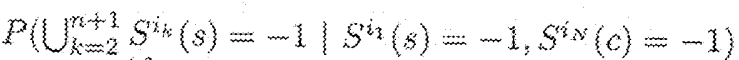

$$
\begin{aligned}
& -P\{\}_{k=2}^{m i n} S^{i}(0)=-\xi\left\langle S^{i}(0)=-\left\{, S^{i N}(0)=-i\right\}\right.
\end{aligned}
$$

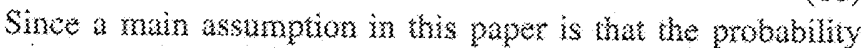

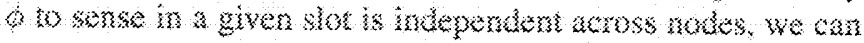

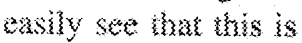

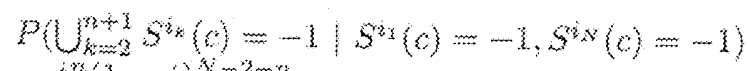

$$
\begin{aligned}
& =\phi^{n}(3-6)^{N-2 m ; z}
\end{aligned}
$$

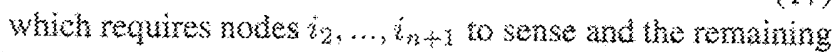
$N-2-n$ rodes wot wo sense in the sersing shot of $i_{3}$. As a result, we can see that the probability of that a node ix

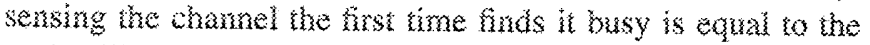
probubility that one of the remaining $N-$ nodes sense the chanme successuly and send, independenty of he node $i_{N}$. We note this as

$$
\alpha=P\left(N(s)=-n \mid S^{N}(c)=-1\right)=P(M(s)=-1)
$$

where $M$ was defined to be the medim without the current node $N$. Indeed, it is only the activity of the other nodes that potentially cause a sensing node to fond the nedium occupied.

Thus

$$
\alpha=L\left[1-(1-\phi)^{N-1}\right](1-\alpha)(1-\beta)
$$

From this, we can derive a second expression for $\phi$ :

$$
\phi_{2}=1-\left[\left(1-\frac{\alpha}{L(1-\alpha)(1-\beta)}\right)\right]^{\frac{3}{N-1}}
$$

A third retation is needed to be able to solve the system and determine the operating point. For this purpose, we kerive an expression for $B$. A backet ransmission stars when the

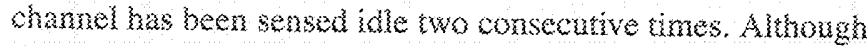

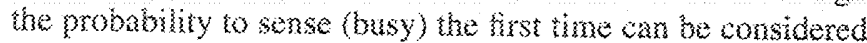

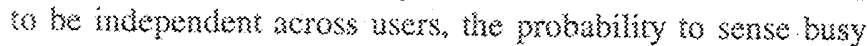

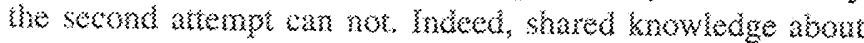

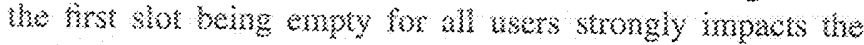

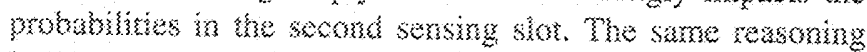

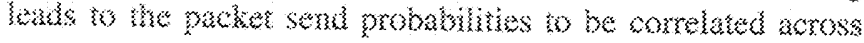

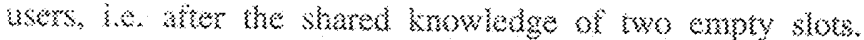

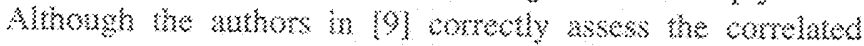

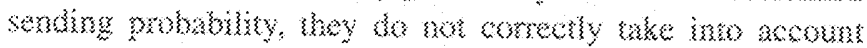

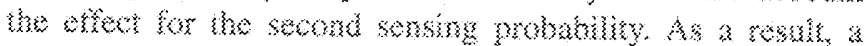

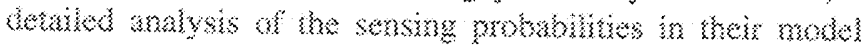

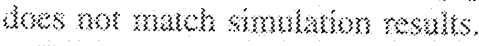

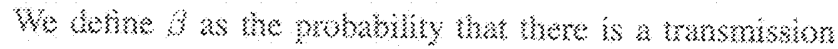

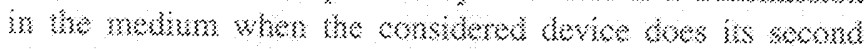

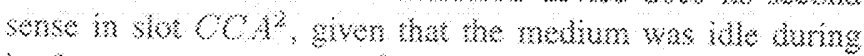

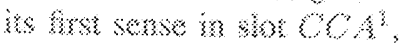

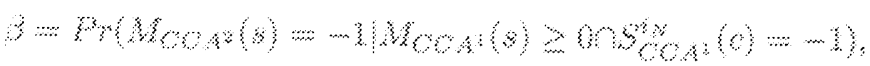

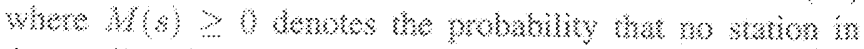

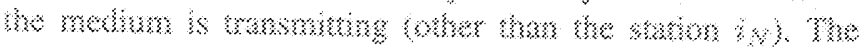

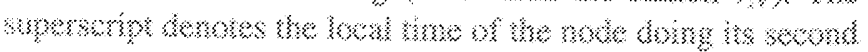

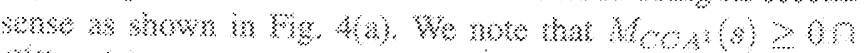

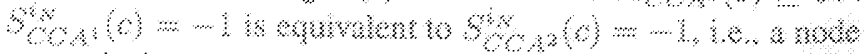

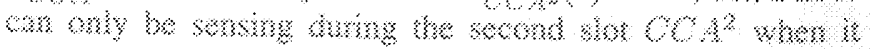

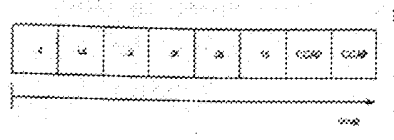

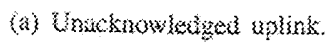

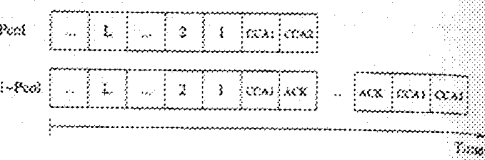

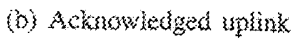

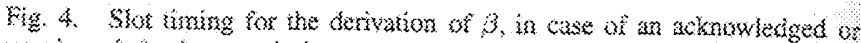

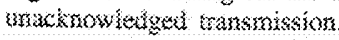

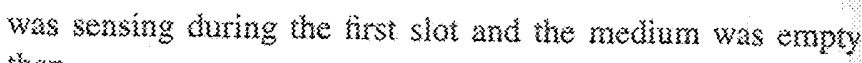
knexp.

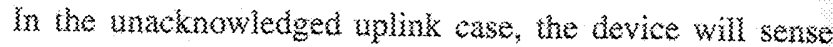
busy only if some other mode in hise medulum was sensing its second time during our device's hrots sense and sarted a new transmission in slot $C C A^{2}$. This can only happen if this node stated sensing in shot $\left(M_{i}(c)=\ldots-1\right)$ and the channel was then ide $\left(M_{l}(s) \geq 0\right)$.

That is

$$
\begin{aligned}
\beta= & P\left(M_{1}(s) \geq 0 \mid\right. \\
& \left.M_{1}(c)=-1, M_{C C A^{3}}(s) \geq 0, S_{C C A^{2}}(c)=-1\right) \\
& \times P\left(M_{1}(c)=-1 \mid M_{C A^{2}}(s) \geq 0, S_{C C A^{3}}(c)=-1\right) \\
= & P\left(M_{1}(s) \geq 0 \mid\right. \\
& \left.M_{1}(c)=-1, M_{C C A^{1}}(s) \geq 0, S_{C C A^{3}}^{i_{N}}(c)=-1\right) \\
& \times P\left(M_{1}(c)=-1\right)
\end{aligned}
$$

Kere $P\left(M_{1}(s) \geq 0 \mid M_{1}(c)=-1, M_{C A^{2}}(s) \geq\right.$ $\left.0, S_{C C A^{2}}^{\hat{i}_{N}}(c)=-1\right)$ is the probability that a given idle slot is preceded by another idle slot when a node is sensing. Also, the last simplification to $P\left(M_{1}(c)=-1\right)$ is possible since the probability to star sensing is independent of the medium status during that slot or the slot following. We can see that

$$
\begin{aligned}
& P\left(M_{1}(s) \geq 0\right. \\
& \left.M_{X}(c)=-1, M_{C O A^{3}}(s) \geq 0, S_{C O A}(c)=-1\right)
\end{aligned}
$$

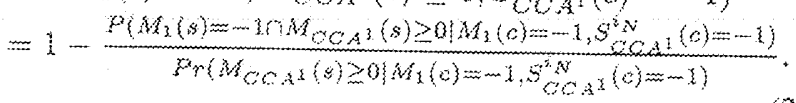

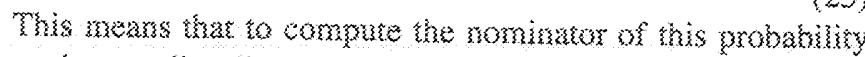

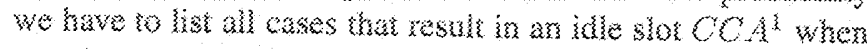

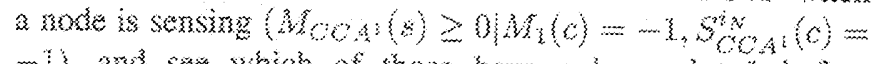

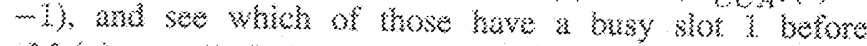

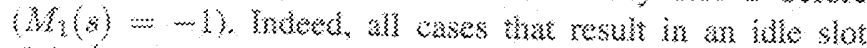

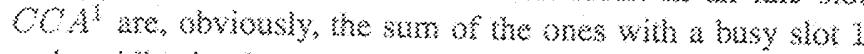

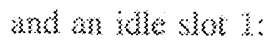

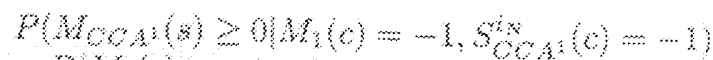

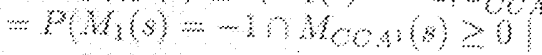

$$
\begin{aligned}
& \left.M_{1}(0)=\cdots, s_{\infty}(0) \cdots \cdots \cdot 1\right)
\end{aligned}
$$

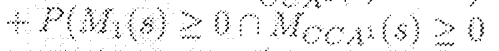

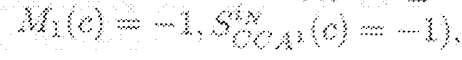

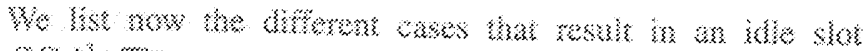

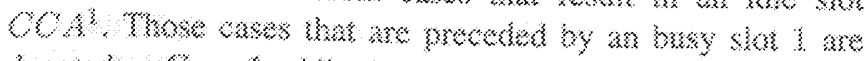

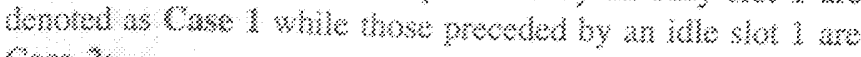
\% $8 \times x \times$

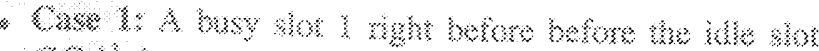

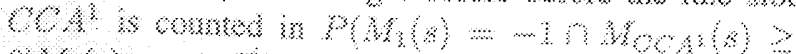

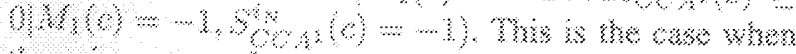

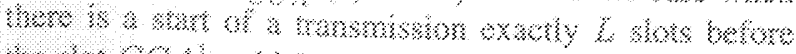

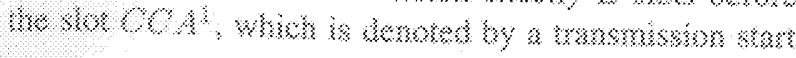




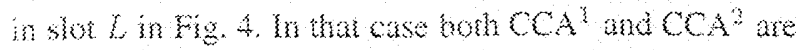

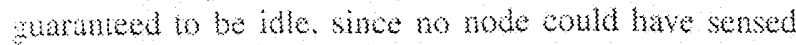

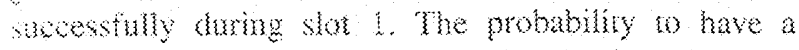

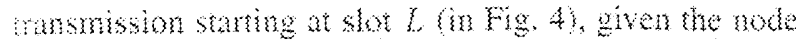

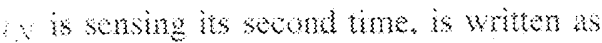

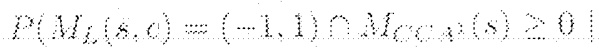

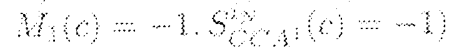

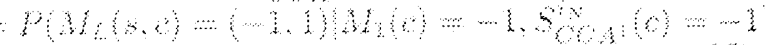

The sep is based on the tack bat when a transmission whes at slot L stor COA is guaranted to be idle. From

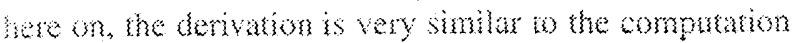

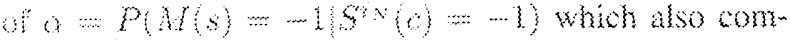
pues the probabiaty that the medum is busy conditioned

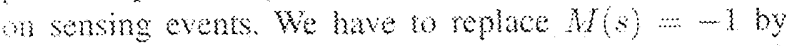
$A(s, \theta)=(-1,1)$ and $S(s) \cdots-1$ by $S(s, c)=(-1,1)$ (3) Eu.(4). This whll result in considering only $E_{3}$ in Q $(15)$, hence $P(s(s, c) \cdots(-1,1))=\phi(1-\alpha)(k-\beta)=$ $P$. Next, the conditioning here depends on nou in

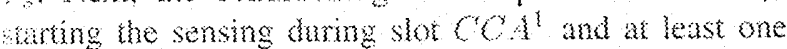
wher of the $N$-.. Inodes stating sensing dumg slot 1 . This linits the number of nodes that are free to stan a manmission at slot . Allough it is possible for in to wart a transmission at slot $L$ and start sensing at slot $C A^{3}$. clearly the nodes starting their sense at slot 1 cannot sart a transmission at slot $L$. Assume that $x$ nodes we staring a transmission at slor 3 . Resultingly, it is mssible to show that

$$
\begin{aligned}
& P\left(M_{1}(s, c) \cdots(-1,1) S_{0,}(0) \cdots-i\right)
\end{aligned}
$$

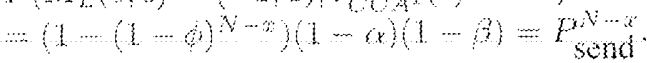

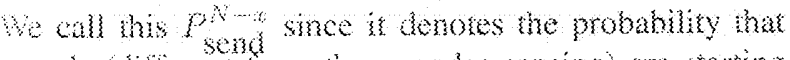

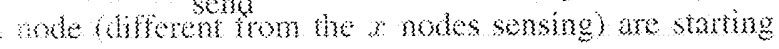

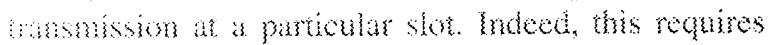

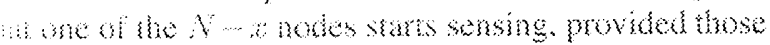
wing events are sucestul.

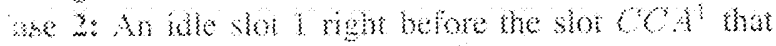

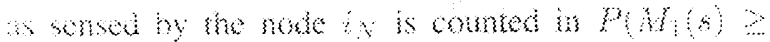

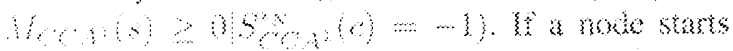

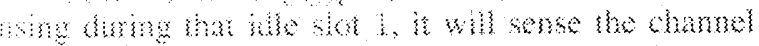

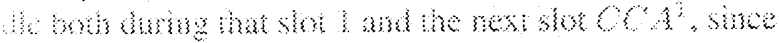

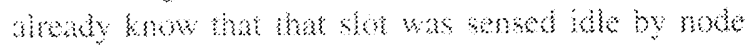

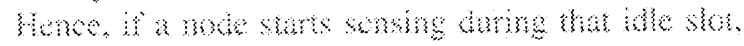

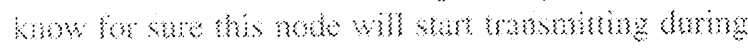

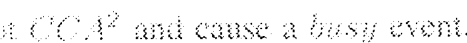

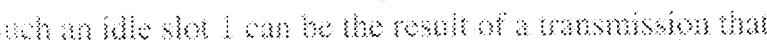

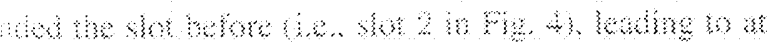

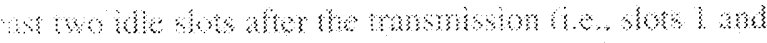

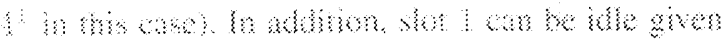

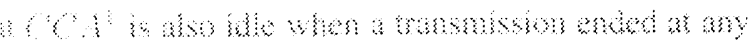

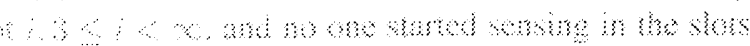

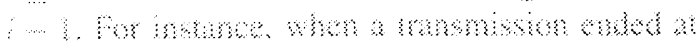

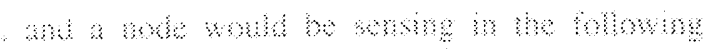

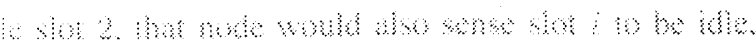

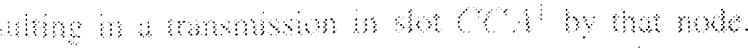

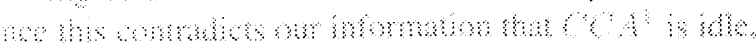

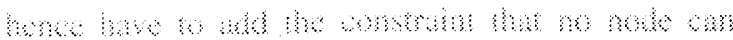

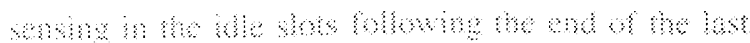

Wunmision. We can sum un al the posible cases that

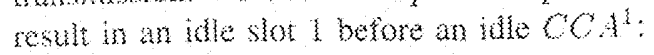

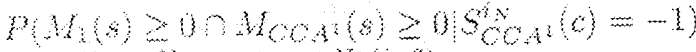

$$
\begin{aligned}
& \sum_{2}^{\infty} p_{\operatorname{send}}^{N}\left(1 \cdots \cdot \varphi^{N}\right)^{(i n 2)} \text {. }
\end{aligned}
$$

Here $P A$ is the probabliky that a node is staring a manmission at a partoubar sot, as derved betore. We

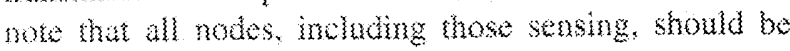
considerad here.

Finally, u complete the computation of 9 in $\mathrm{Cq}(22)$ the probability that some nota stats sensing durng shot is

$$
P\left(M_{1}(0)=-1\right)=\left(1-(1 \cdots 6)^{N-1}\right)
$$

When 3 is given by

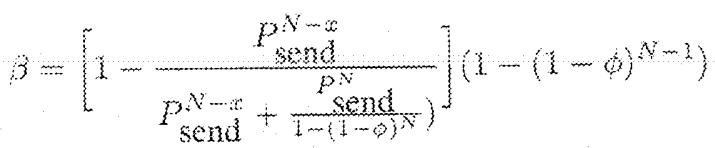

which for large $N$ can be simplifed to;

$$
\beta=\left[1-\frac{1}{1\left(1+\frac{1}{1-(1-\phi)^{X}}\right)}\right\}\left(1-(1-\phi)^{N}\right)
$$

from which one obtains

$$
\phi_{3}=1-\left(1-\frac{\beta}{1-\beta}\right)^{1 / N}
$$

The network operating point as determined by $\phi, \alpha$ and $\beta$ is determined by solving the three non-linear Equations $13,19,3$. These the values are sulveiem to detemine the network turoughput and energy consumption achieved anting operation, as we will show in Section V. First, we however extend the model to cover asso acknowledged uplink towthe.

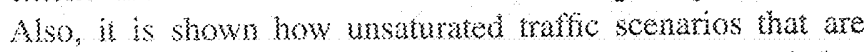
relevant in the context of sensor networks can be nodeled.

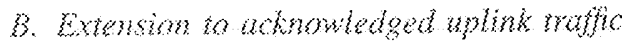

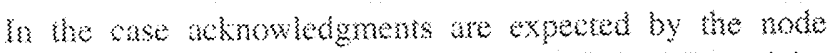

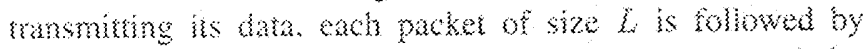

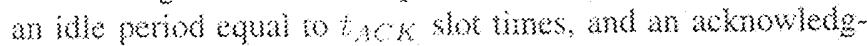

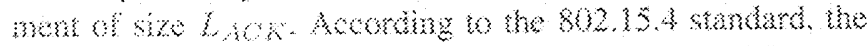

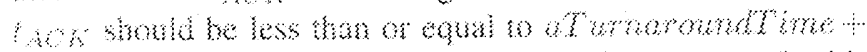

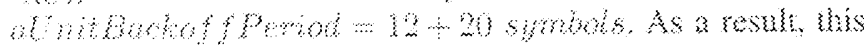

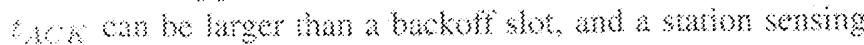

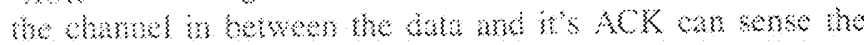

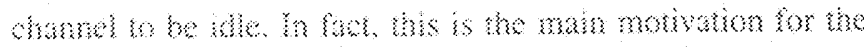

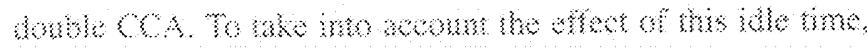

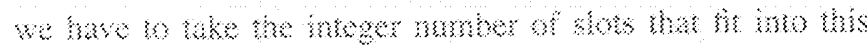

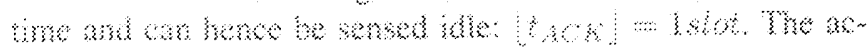

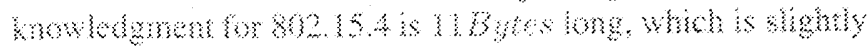

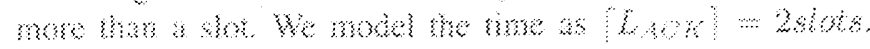

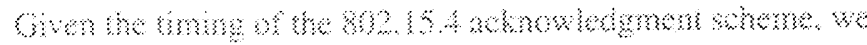

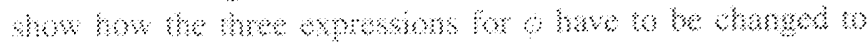

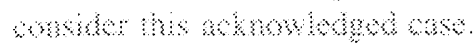

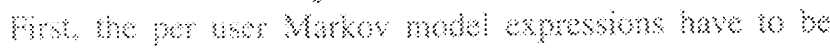

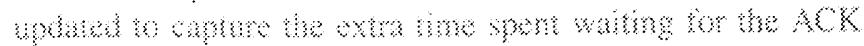

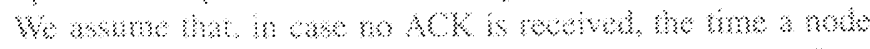

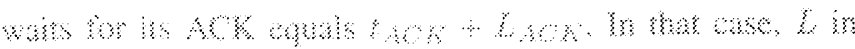




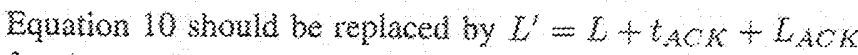
for $\phi_{y}$.

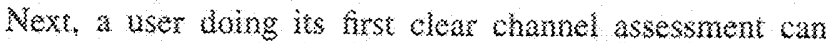

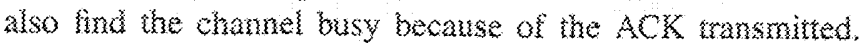

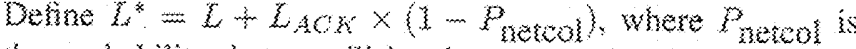

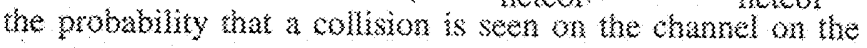

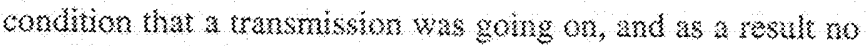

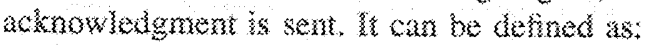

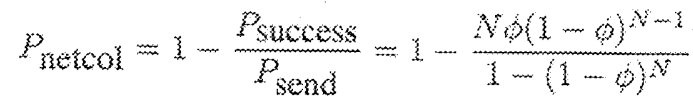

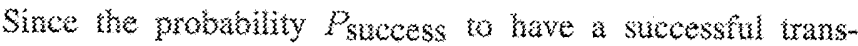

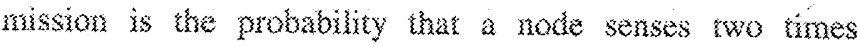
successfuly, and ahe others not:

$$
\text { Psuccess }=N \phi(1-\phi)^{N-3}(1-\alpha)(1-\beta)
$$

and the probability $p$ swocss that a node in the network sends a packet is the grobability that at least one node is sensing successfully

$$
P_{\text {send }}=p_{\text {Send }}^{N}=1-(1-\phi)^{N}(1-\alpha)(1-\beta) .
$$

To determine the new expression for $\alpha$, we have to replace $L$ in $\mathrm{Eq} .19$ with $\zeta$ for $\phi_{2}$.

Finally, we have to ake into account the fact that a user carn find the channe clear during the first clear chamel assessment $C C A^{2}$ when this slot coincides with the time berween data and acknowledgment $t_{A C K}$. When the data transmission was successiul, an acknowledgment will follow and the user doing its second clear channel assessment $C C A^{2}$ will tha the chamel busy. Whis is different compared to the unacknowhaged case, where a second busy serse can only ocus with a new transmission stan, which leck to the condition that some noue had wo be sensing before in shot 1

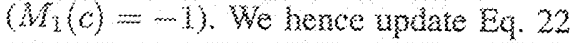

$$
\begin{aligned}
& \text { Gax } \quad \cdots(h / n) \geq \eta
\end{aligned}
$$

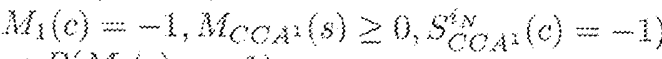

$$
\begin{aligned}
& x)\left(B / b_{1}(c)-1\right) \\
& \because 2 \text { was }
\end{aligned}
$$

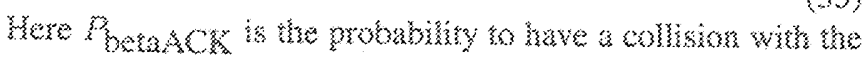

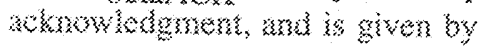

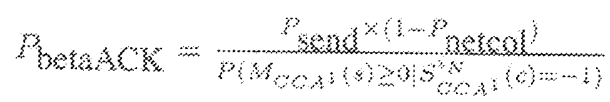

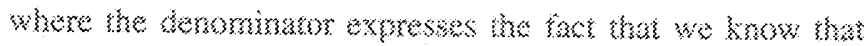

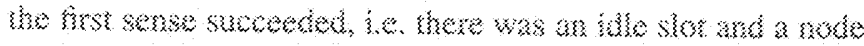

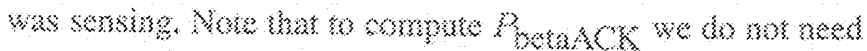

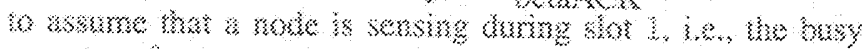

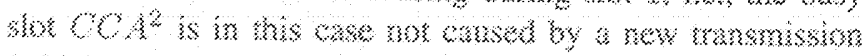

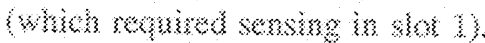

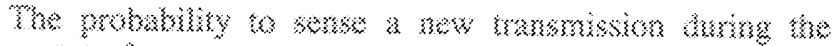

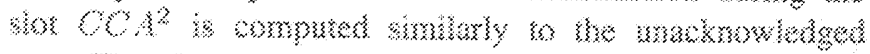

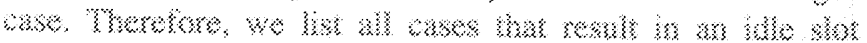

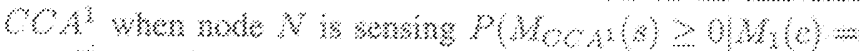

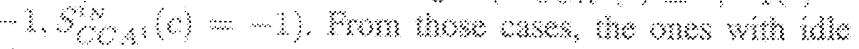

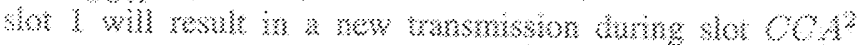

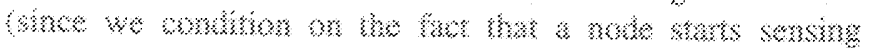

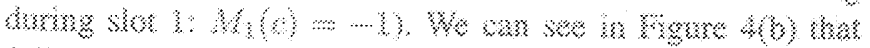

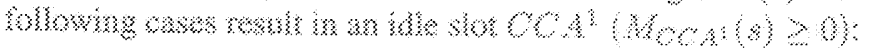

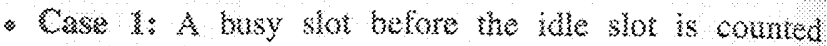

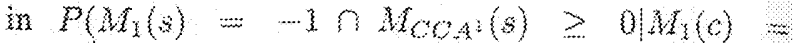

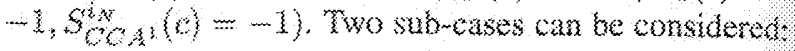

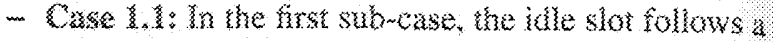

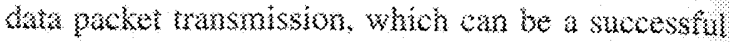

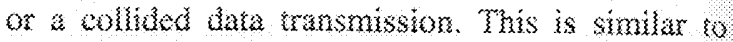

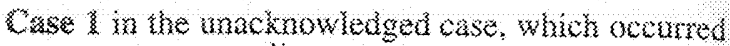

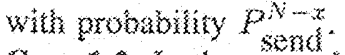

- Case 1.2. In hace second sub-ease, he busy slot just before the ide sho is in berween a data packet and the acknowledgment following a successtuh data

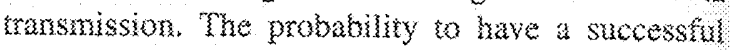

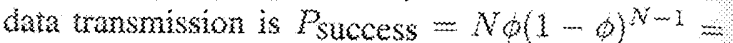
$P_{\text {send }} \times\left(1-P_{\text {netcol }}\right)$. This approximates the probability to have Case 1.2, following similar dervations as we did berore. Indeed, in onder to derive the correct probability for his subcase, we shoud substivte $N$ by $N$ - where $x$ is the number of nodes sensing during slot 1. However, since we will neglect this $x$ to derive a compact expression for $\beta$ later, we do not compute it exactly here.

- Case 2: An idle slot I right before slor $C C^{1}$ is counted in $P\left(M_{1}(s) \geq 0 \cap M_{C C A^{1}}(s) \geq 0\left\{M_{1}(c)=\right.\right.$ $\left.-1, S_{C C A^{1}}^{i_{N}}(c)=-1\right)$. This can happen when an acknowledged successful ransmission or an unacknowledged unsuccessul transmission ended in shot 2 . The sum of both events is $P_{\text {send. Alternatively, the transmission }}$ ended before slot 2 , but no node started sensing after the end of the ransmission, untl slot 1. The resuling probability for this case is hence the same as in the unacknowledged Case $2: P\left(M_{1}(s) \geq 0 \cap M_{C O A}(s) \geq\right.$ $0)=\sum_{i=1}^{\infty} P_{\text {send }}\left((1-\phi)^{N}\right)(i-1)$.

The expression wr $p$ in the roknow

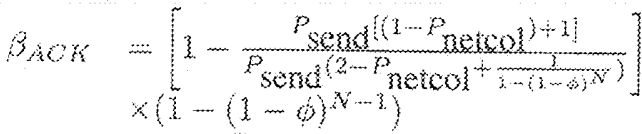

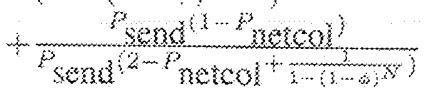

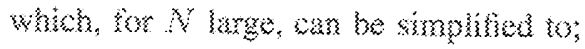

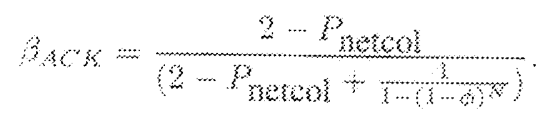

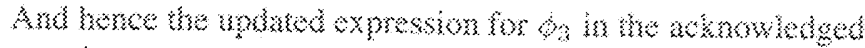
)

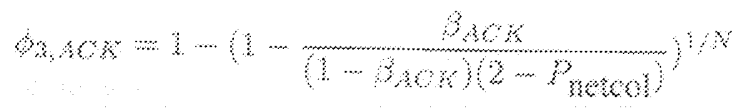

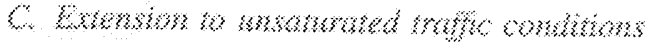

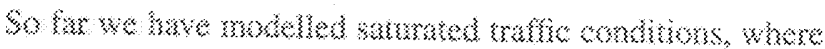

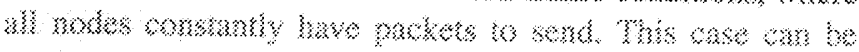

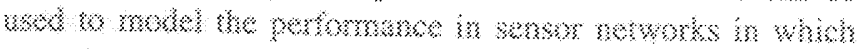

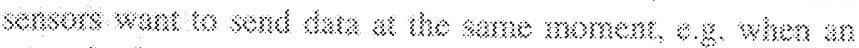

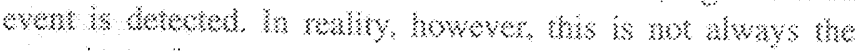

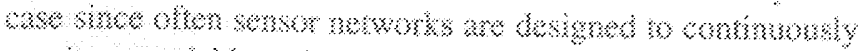

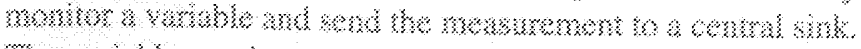

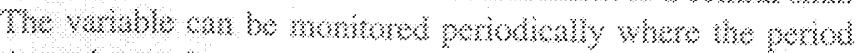

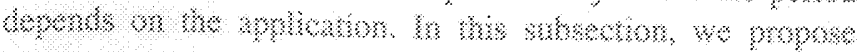




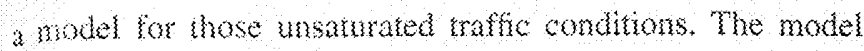

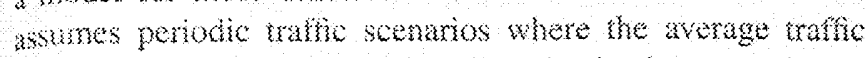

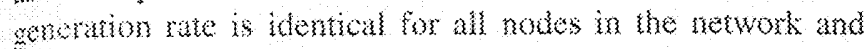
consul over trmo.

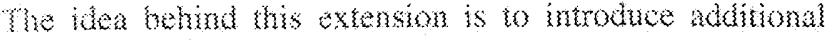
stas foluwing each geriobe transmiston or manmission

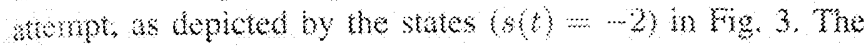

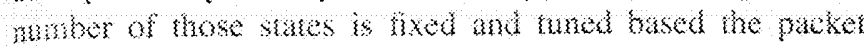

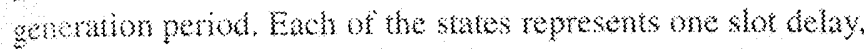

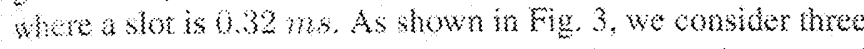

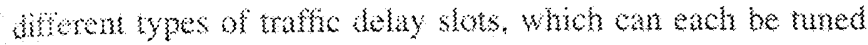

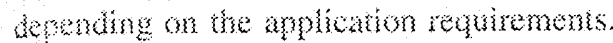

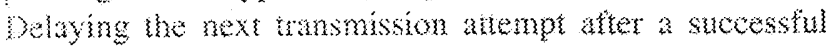

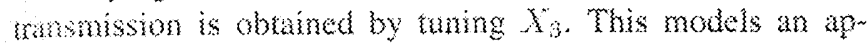
blacton where a varable should be reported reliably to a comal sink approximately every $T$ slots, where $Y=X_{3}+Z_{3}$ whin $W_{3}$ the expected wathig time man the and of the

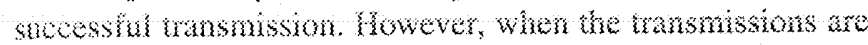
no acknowledged, it is not possible to know if the rans-

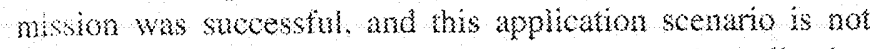
possible. Moreover, it could be the sensor network application policy to not report a measurement more than once, e.g. to save energy, when reliability is not the main besign goal. If the tansmission talled, a more recen measurement will be transmitted latex, at a monent where there is (hopefully) less network activity hence less colision probability. In those cass, $X_{2}$ is the additional deky that should be added before the next periobic packet transmission. Finally, in some energy seisstive applications, it could be the policy to only contend wice to send one unit of intormation and resume transmission when that single contenton cycte ends. In the case, contention curey consumption is decreased as much as possible by dowing transmissions whenever the channel is defected to the very bus on that case, the delay $X$, is addea wher each

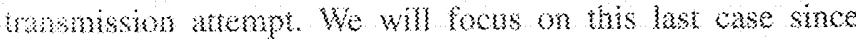

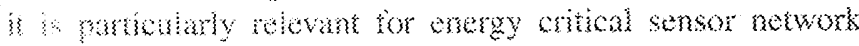
ankathons

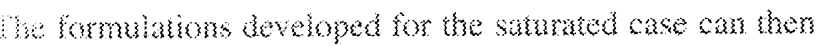

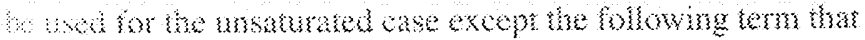

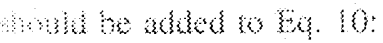

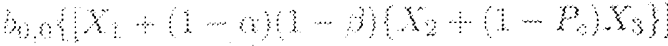

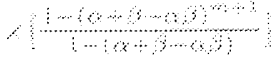

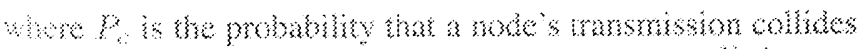

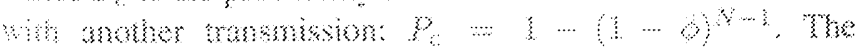

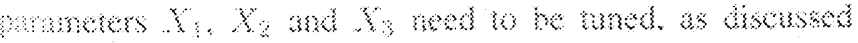

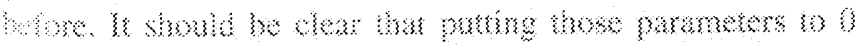

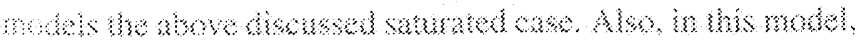

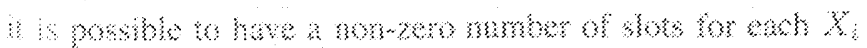

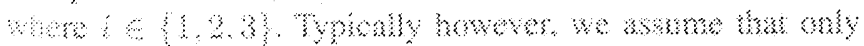

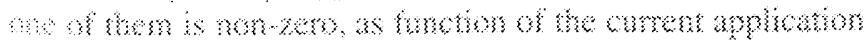
armenks

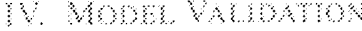

\section{SmmWhm Koll}

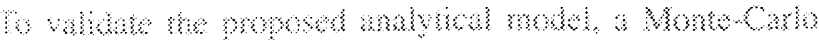

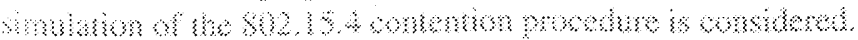

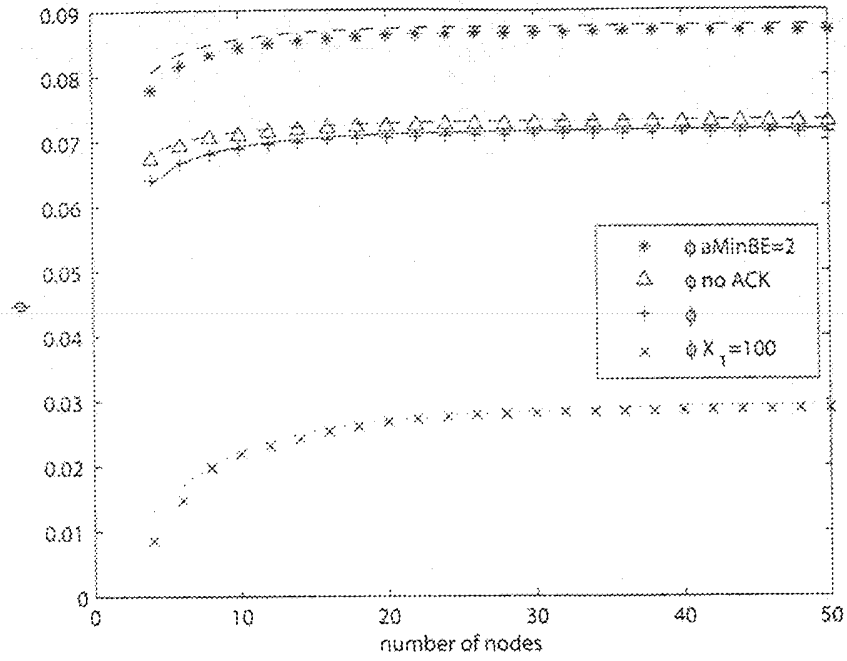

Fig. 3. Probabinty to stan sensing $\phi$ for some sakurated newworks und for peritobic traftic.

We developed therefore a vector-based simulator in Mallab. The pseudo-code of the simulation loop is depicted in Algorithm 1. Th can easily be verifed that it matches the 802.15.4 CSMA/CA algorithin as depicted in Fig. 2. We only depict the cole for unacknowledged and satumted uplink traffe. Extension to the other traffic scenarios is straightorward. Since the 802.15.4 CSMAJCA schene can be captured with a hxed duration backof slot, it is possible to consider each simulation step a new slot. The system state during each slot is tracked using state vectors of dimension $N$, which is the number of nodes. Three vectors represent the values of $N B$, $C W$ and $B E$. A fourth vector deky represents both the state of the node ( 1 if idle, 0 if ransmiting and contention,

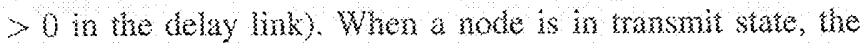

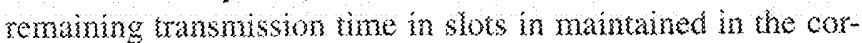

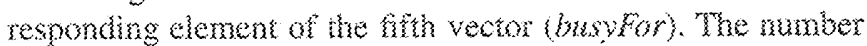

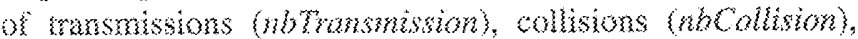

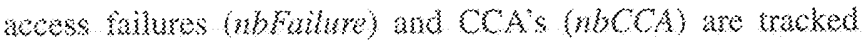
for a simulation nu of $?$.

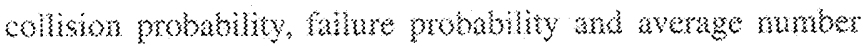

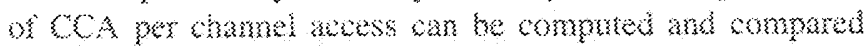

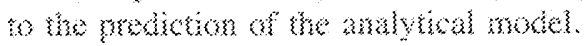

\section{3). Wode? Wuknatios?}

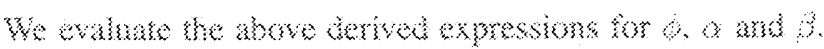

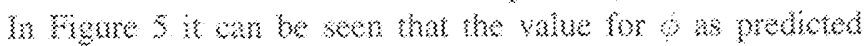

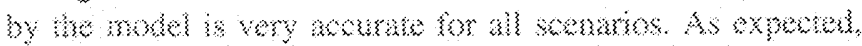

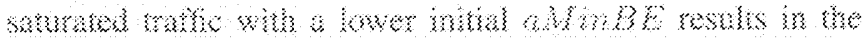

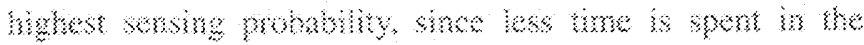

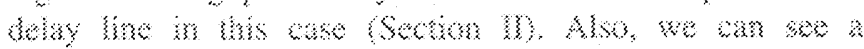

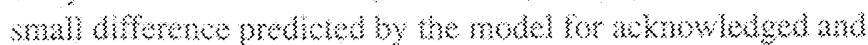

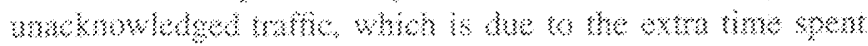

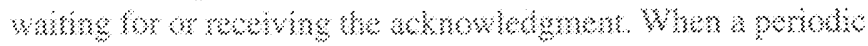

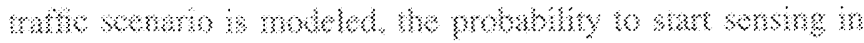

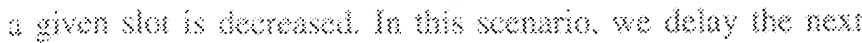

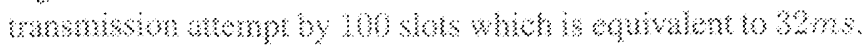

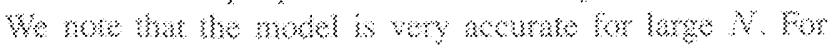

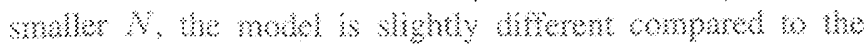




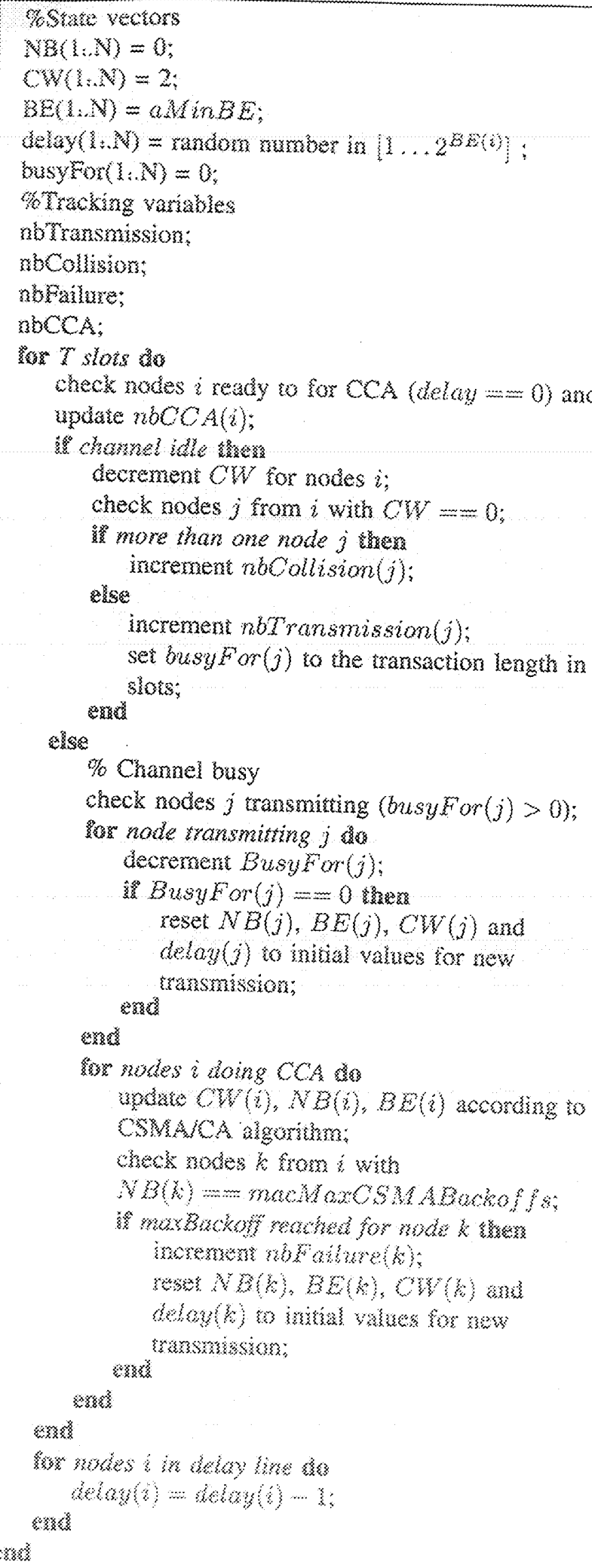

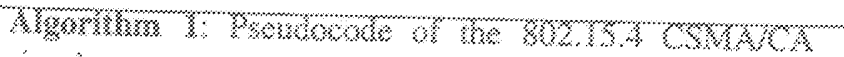
wimantars\%

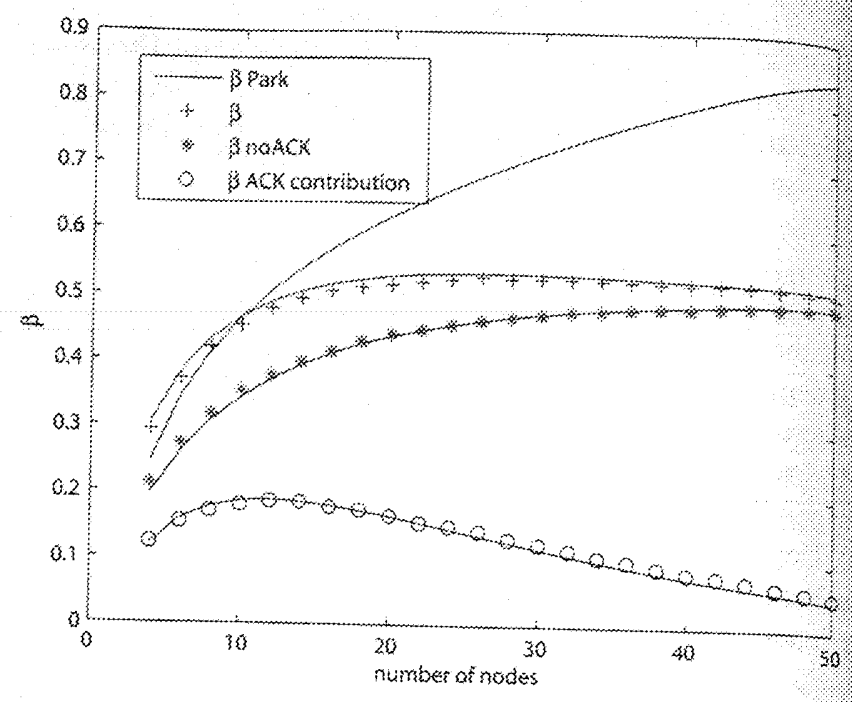

F⿳. \&. Conutional mobability $\beta$ to sense busy when sensing the scons sioc

simulation since the approximations we used to compute $\beta$ as function of $p_{\text {send. }} P_{\text {netcol }}$ and $P_{\text {success are only valid }}$ for larger $N$. Next, we note that our basic assumption that the probabilities to start sensing of the different nodes is independent is more accurate for larger N. Indeed, in [12] it has been shown that, when the number of stations increases - i.e., large $N$-. stations tend to become independent.

The ditherence between the proposed model and the model in 19$]$ is illustrated in Fig. 6 by comparing the results for $\beta$, which is the probability to sense busy during the second $C O A^{2}$. As explained above, 缘e model in 91 fails no corectly model this $\beta$ since it aoes not correctly capture the che tho only a successful $O C K^{2}$ ean result in a second $C C^{2}$. As a resulu, ther expression for $\beta$, and also the network eonulibrim

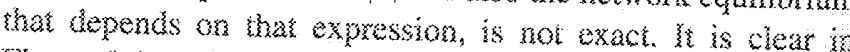

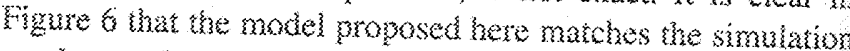

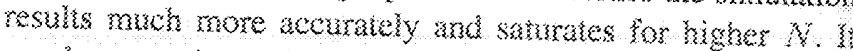

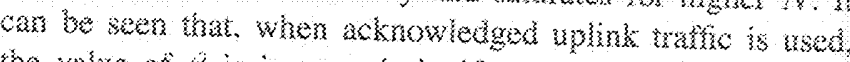

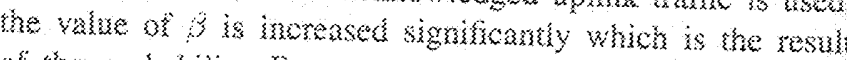

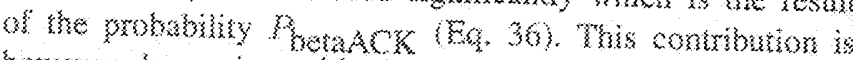

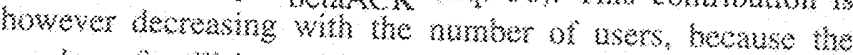

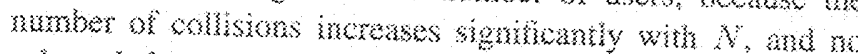

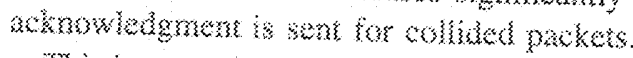

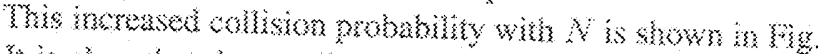

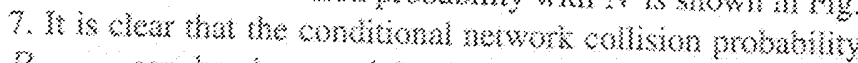

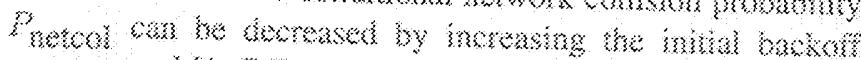

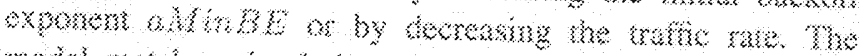

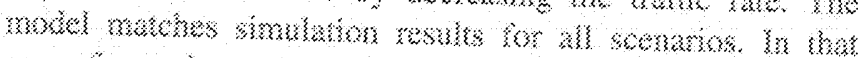

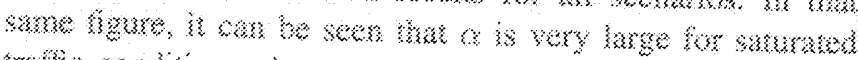

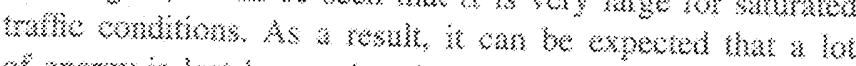

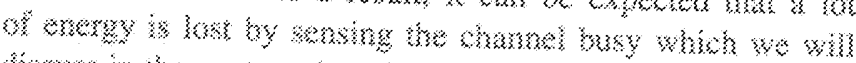

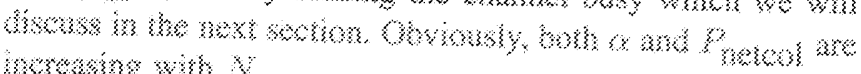
mereasons whis $\mathrm{Y}$.

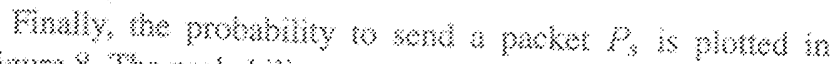

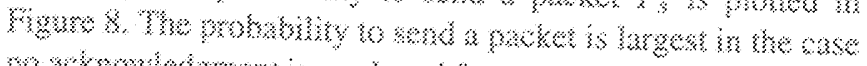

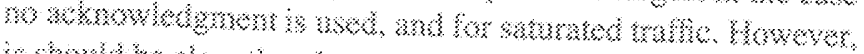

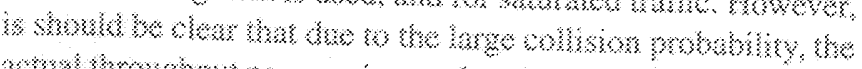

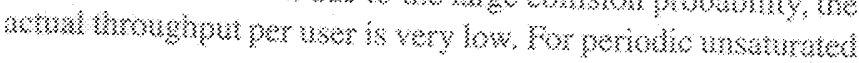




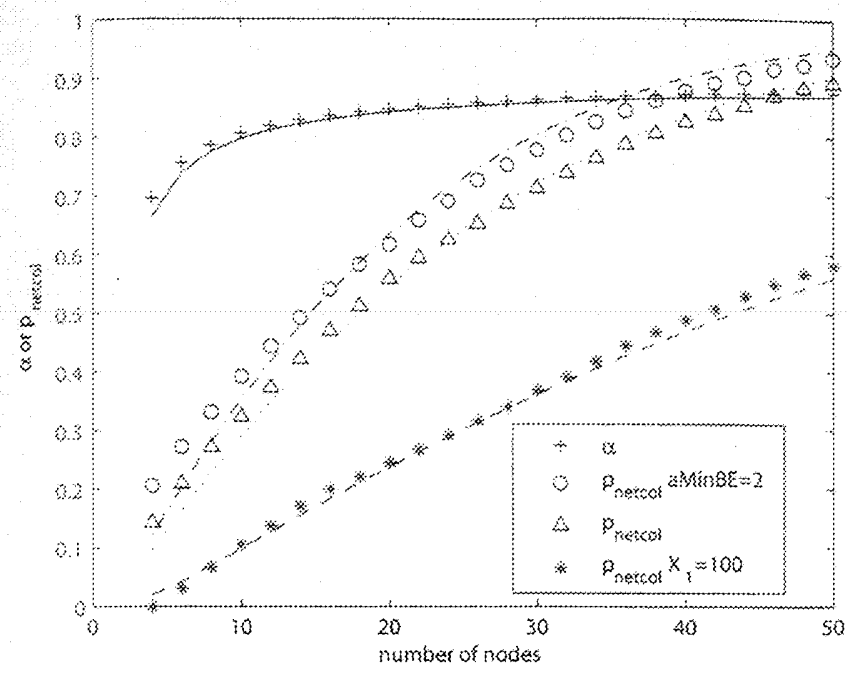

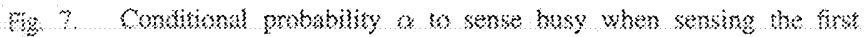

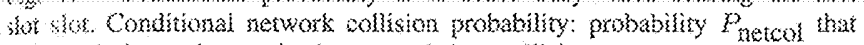
3 minnsmission going on in the network is a collision.

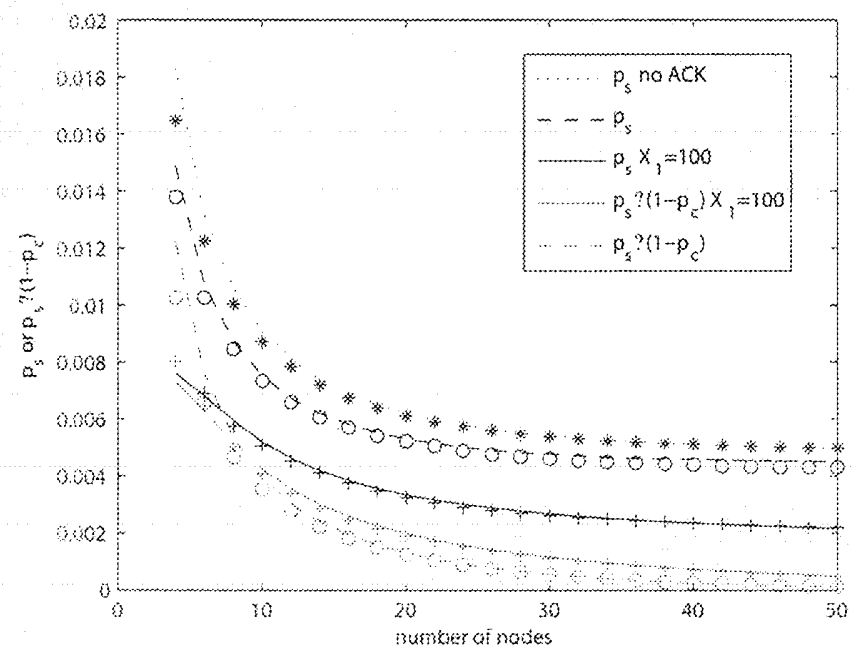

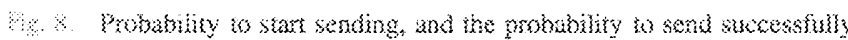

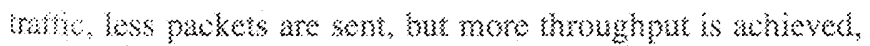

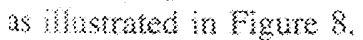

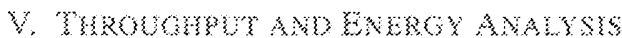

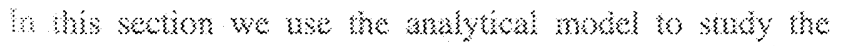

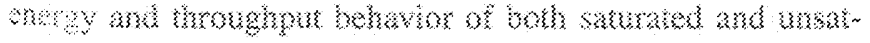

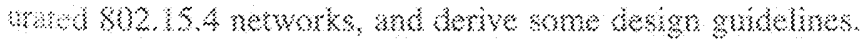

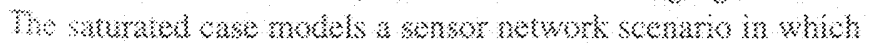

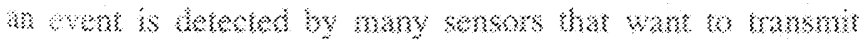

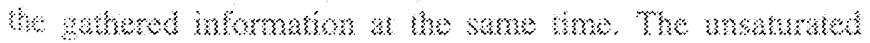

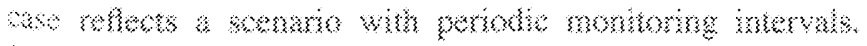

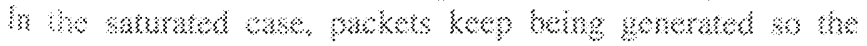

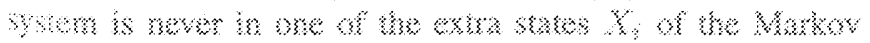

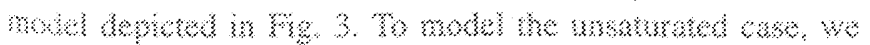

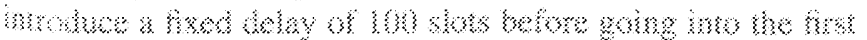

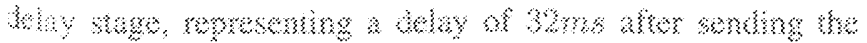

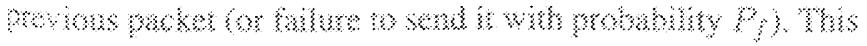

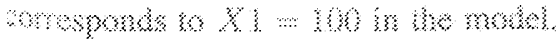

We assme that colluded packets, or packers that fribed

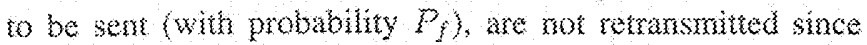

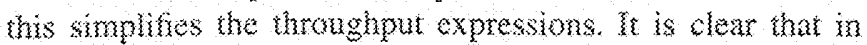

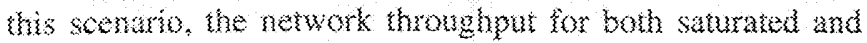

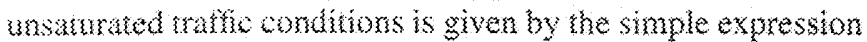

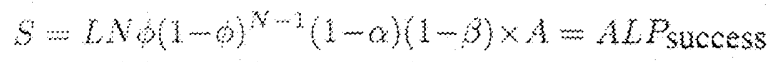

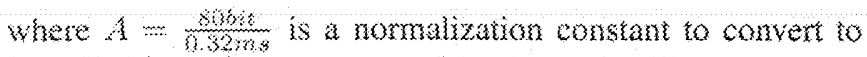

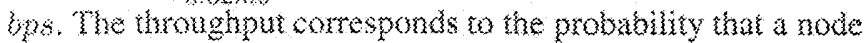
in the netwon stans sersing abone, and has sucess buring its channel assessments.

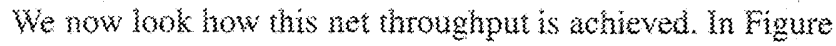

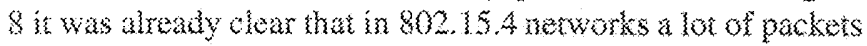
get bost due to collisions, and the actua throughput can be very low. We compare the probability to sure a mansmission atsempt (entering kelay line), the prokbility o star sending, and the probability that a packet was sent successully. We determine $P$ atrempi, $P$ send and Prucess and plot the breakuown for a set of scenarios in wigure 9 . Only $P_{\text {arempt has not been }}$ determined yes in the motel section:

$$
P_{\text {attempt }}=P_{\text {send }}+N \times P_{f}
$$

where the transmission falure $P_{f}$ for one node is given in $E q$. 11. To compare the efficiency of the protocol, we convert the packet probabilities per slot to bps. According to the 802.15.4 physical layer in the $2.4 G H \approx$ band, a maximum bit rate of $250 k b p s$ is possible.

Since a lot of packets are lose due to collisions, a lower initial Backoff Exponent aM K B E is not optimal in this case. It can be seen in Fig. $9(0)$ that with $a M$ in $B E=2$ more packets are sent, but less net throughput is acheved and a lot of energy is wasted in collded transmissions. For sensor networks that are expected to generate a lot of traffe across

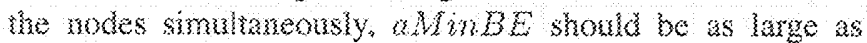

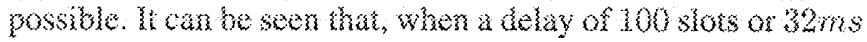

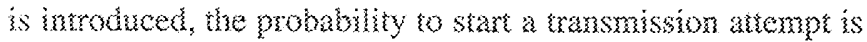

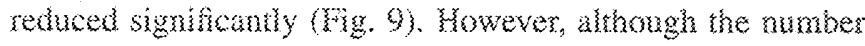

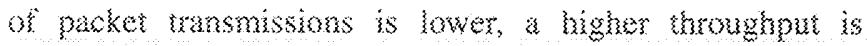

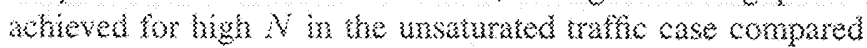

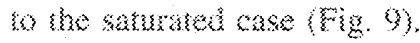

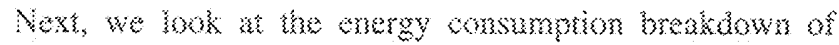

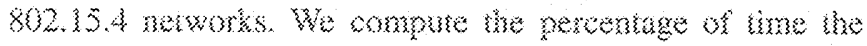

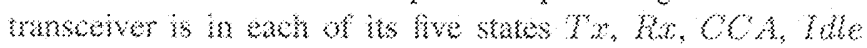

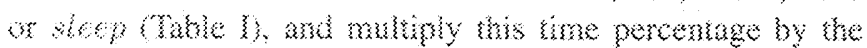

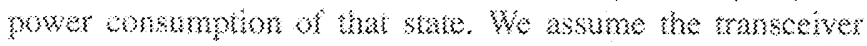

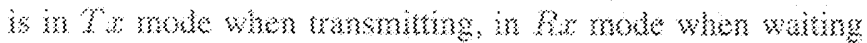

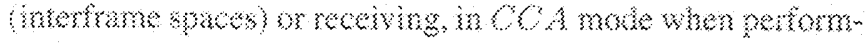

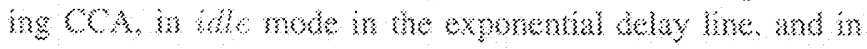

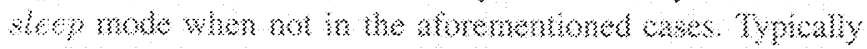

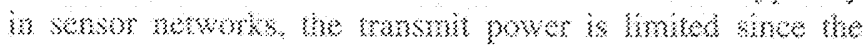

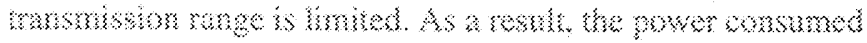

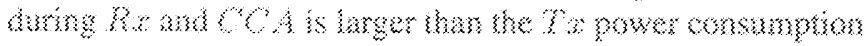

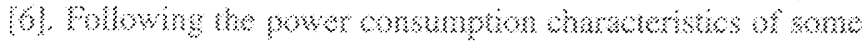

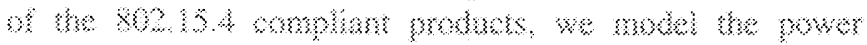

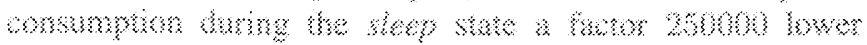

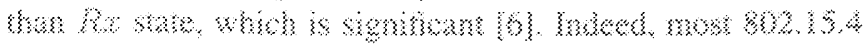

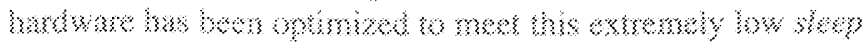

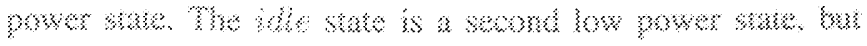

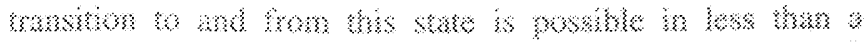




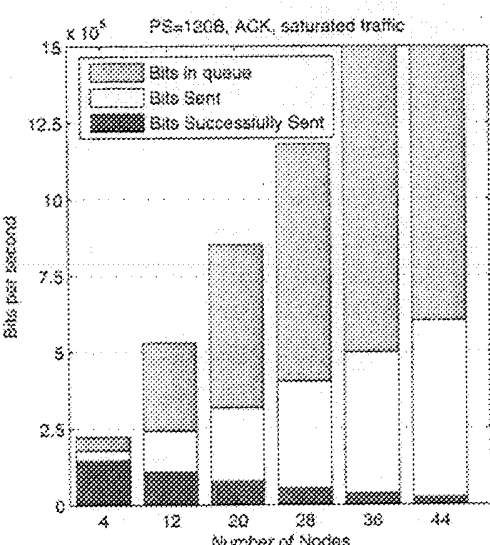

(a) No belay beween ransmit axempres

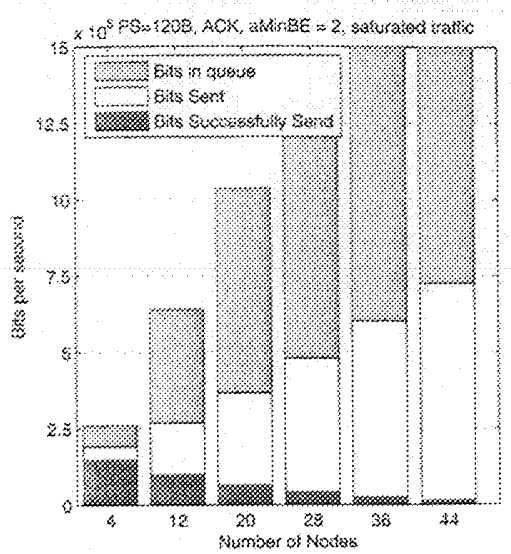

(b) No deby between transulit atempts, lower initual backorf Exponent

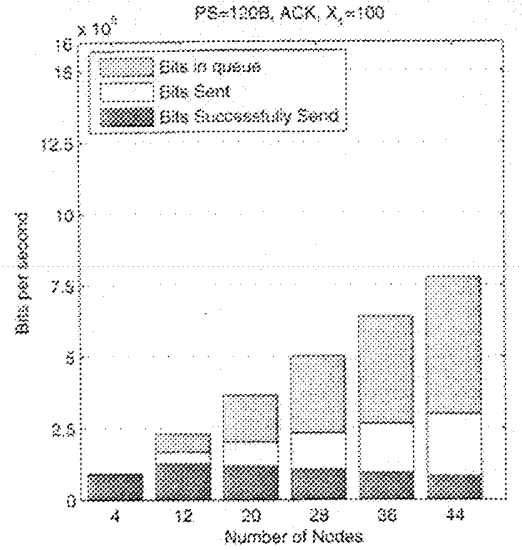

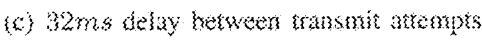

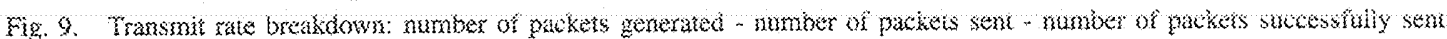

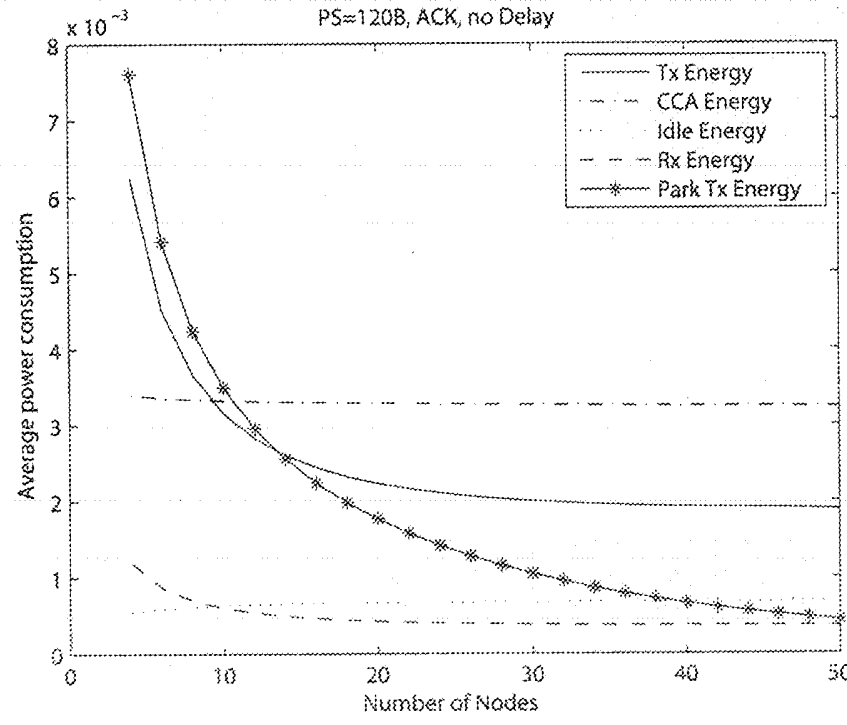

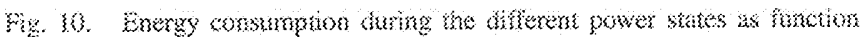

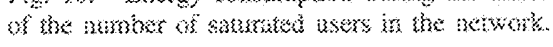

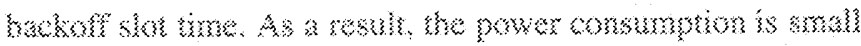

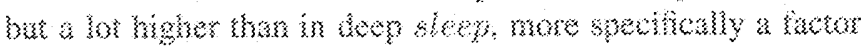

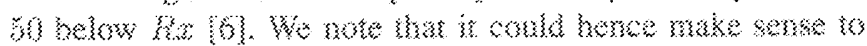

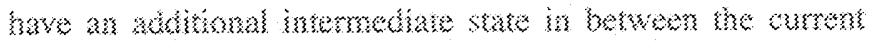

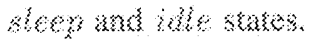

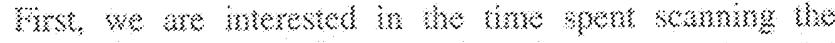

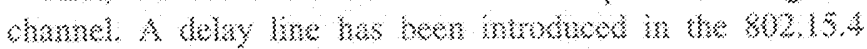

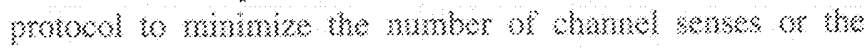

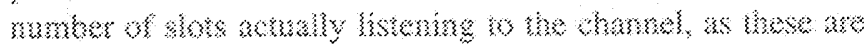

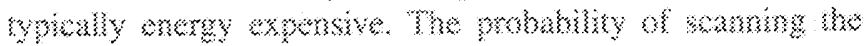

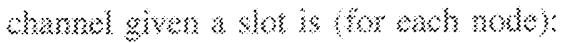

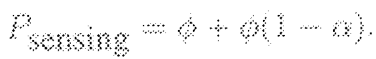

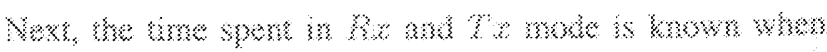

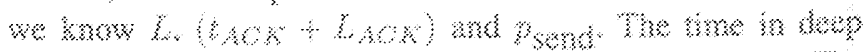

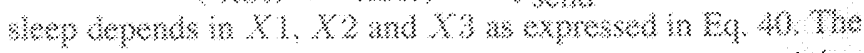

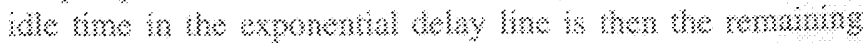

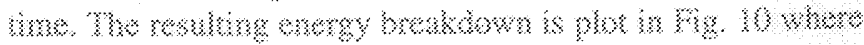

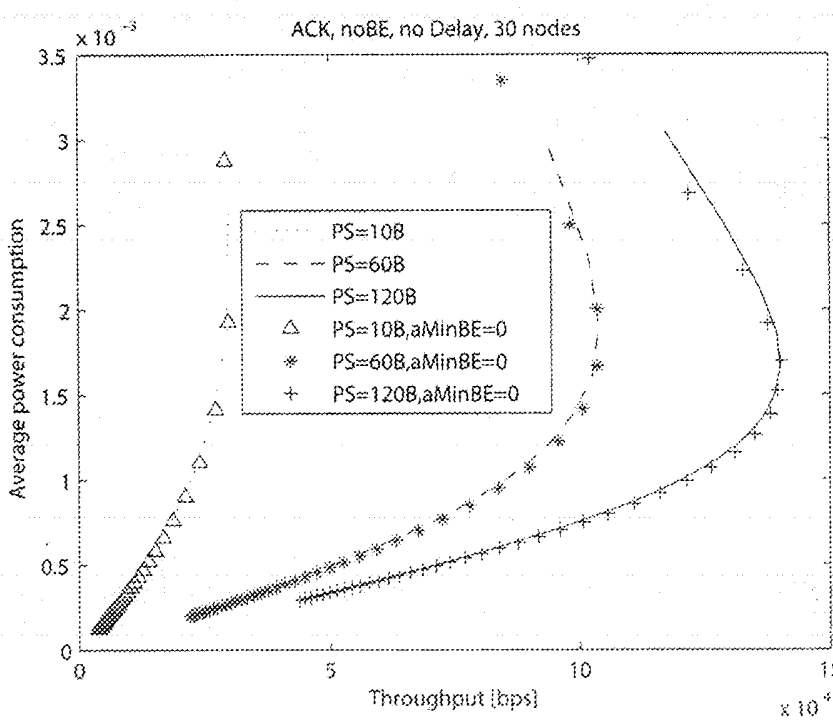

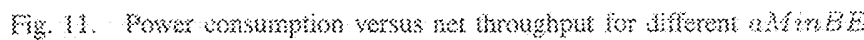
marazecer sempas.

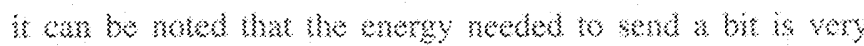

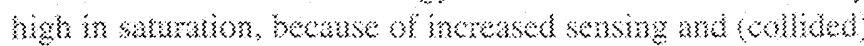

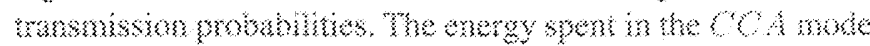

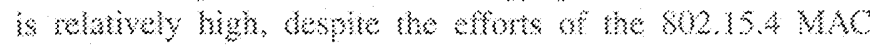

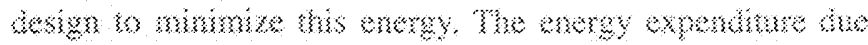

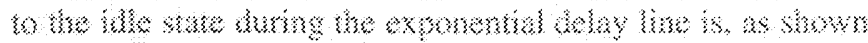

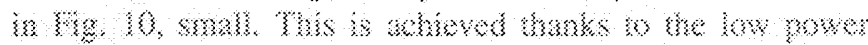

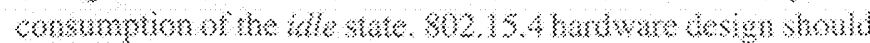

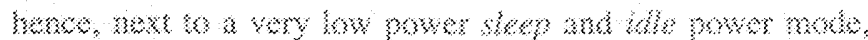

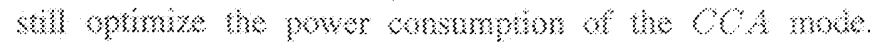

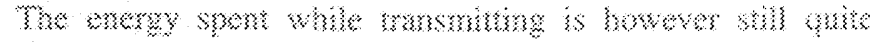

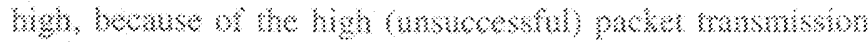

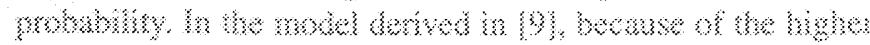

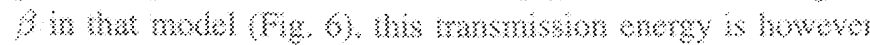

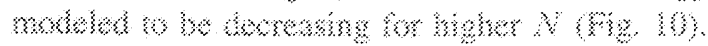

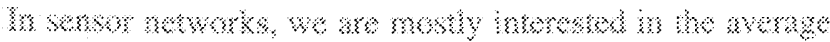

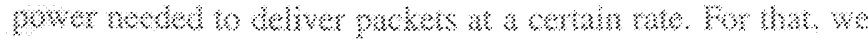

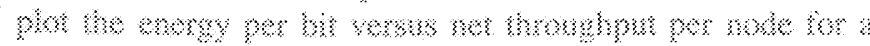

the 
mae of MAC parameter serirgs such as a hin $B E, N B$ and

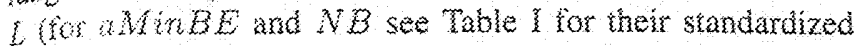

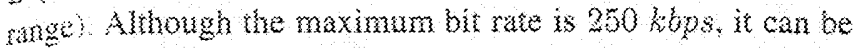

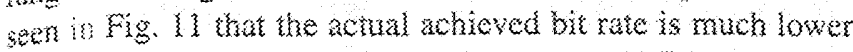
in reariy, As expected, larger packe sizes (1200 in this case pertum the best, bouk hams of power consumption and

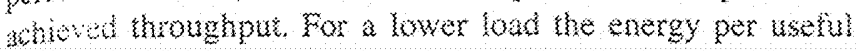

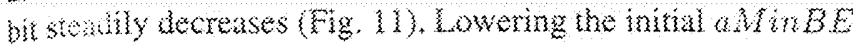
cesils in a very small power consumprion improvement lor a wiven pasket sze. Since the power consumption in the

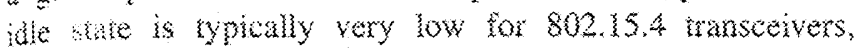
ho gans are very small. Further, we note thut the averuge

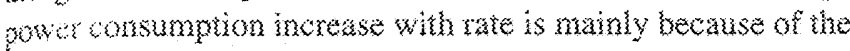
increased $3 x$ power but also becumse of increased CCA power consumption. whors bo decrease hat CCA nower consumption ind have very usefus.

\section{Y. CONCLUSTON}

In this paper, we kave presented an analytical model for the refim access control hyer in IEEE 802.15 .4 standard. The model assumes a kntite number of terminals and ideal chanut conditions. The validity of the analytical model is demonstrated by closely matching its predictions to the simutation results. We tase the analytical model to predict nergy consumption as well as the throughwot of saturated and ussumprat 802.15.4 networks, based on which some desinn guidelnes can be derived. It is shown that for saturated netwoks, it is best to choose a large exponential delay backoff. For msaturated newworks, smaller backofi values improve the energy consumption but these energy savings are very mal. it is also shown that ahough the rege 802.15 .4 CSNAKA mechanism significantly decreases the time and

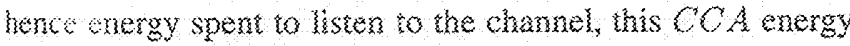
consumpion stul rowesents a major part of the total system ener consumption.

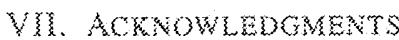

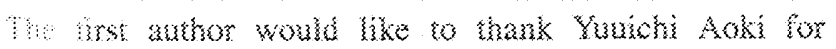

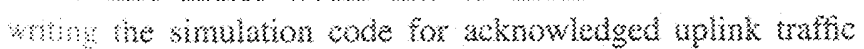

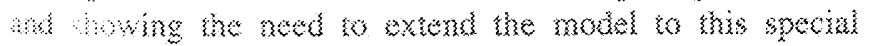

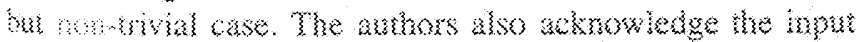

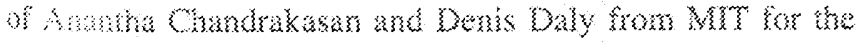
अmon.

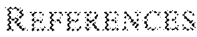

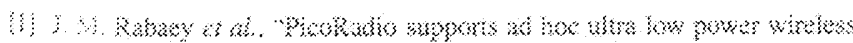

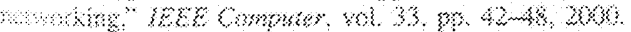

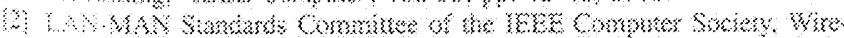

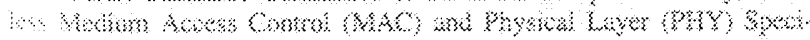

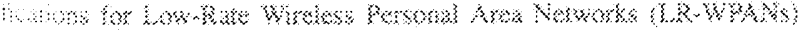
ब. 20

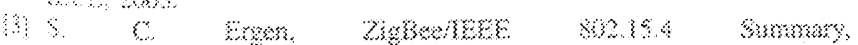

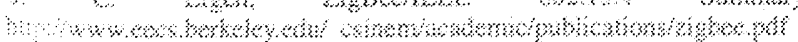

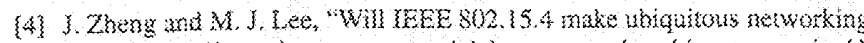

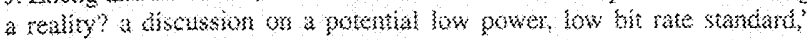

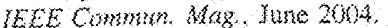

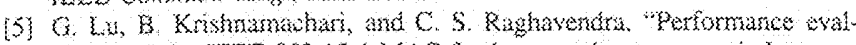
whon of

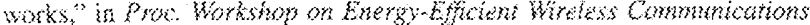

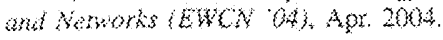

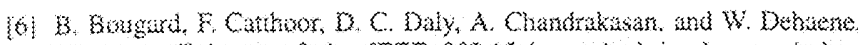

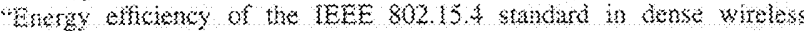

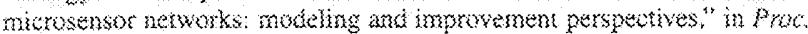

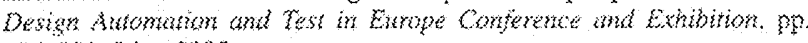
$396-201$, Mas. 2005 .

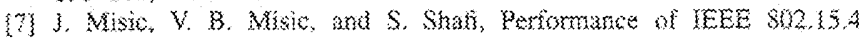

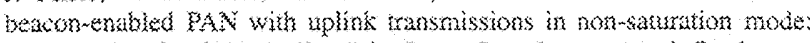

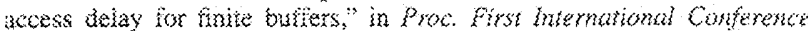

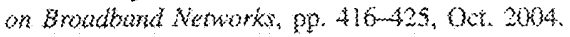

(8) 3. Misic, 5. Shata, mu V. B. Nisic, "The impace of MAC parmeters on the periomance of 802.35 .4 3. A A Hoc Neworks, wot. 3, no. 5. po. $309-528,5 e 0 t .2003$

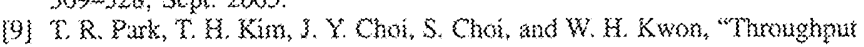
and energy consumption analysis olleES 802.15,A sloted CSMACA;" Electron, Leti, Sept. $200 \mathrm{~s}$.

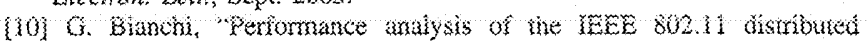

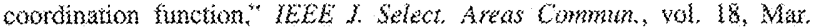
2000.

[11] LAN MAN Standasds Commitee of the ferge Computer Society, Whrejess $Z A N$ medium access control(NAC) and ghysical hyer(PAY) specification, YEEE, MEEE Std 802.11-199? edition, 1997.

[12] M. Ergen, "W-WLAN: intelligen-wireless local area networking" Dec 2004, UC Berkeley, Ph.D. Thesis.

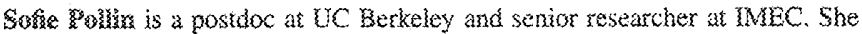
obrained the PhD from the K.U.heuven wh honors in 2006. Her research interests are in wireless communications and networks.

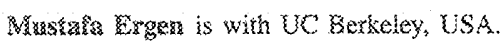

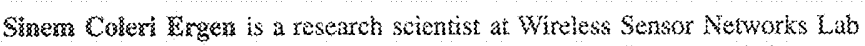

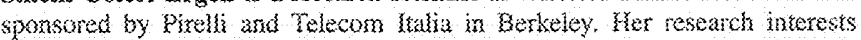

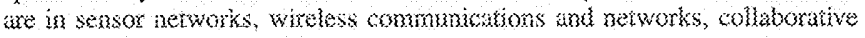
signa procassing and intelkgen transwonation systems.

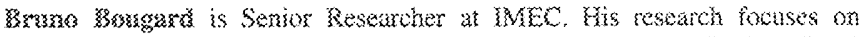

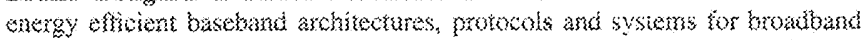

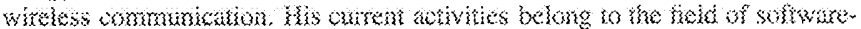
definel rabio basebund procesing

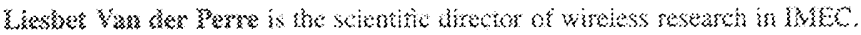

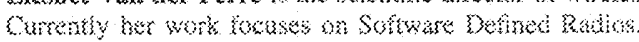

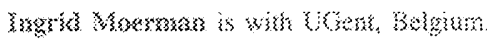

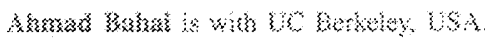

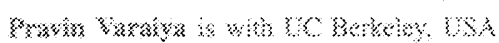

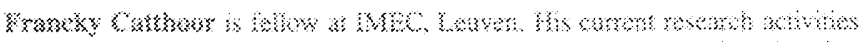

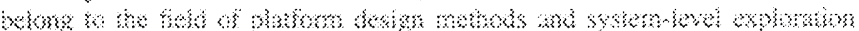

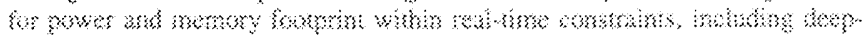
बimtam 


\section{IEEE TRANSACTIONS ON}

\section{WIRELESS}

COMMUNICATIONS

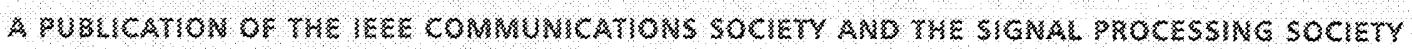
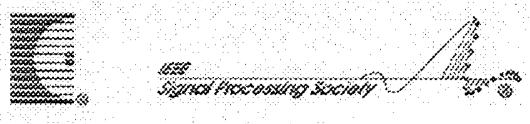

\section{TRANSACTONS LETERS}

Improving Security of RealFime Wireless Networks Through Packet Scheduling ......................... 3273

Xiao Oin, Mohamed Alghamdi, Mais Nijim, Zilhang Zong, Kiranmai Bellam, Xiaojun Ruan, and Adum Manzanares

Frequency-Domain Turbo Equalization and Mutiuser Detection for DS-UWB Systens ..................... 3280

Paraveen Kaligineedi and Vijay $K$. Bhargava.

Code Shift Keying Impulse Modulation for UWB Communications

Serhat Erkucuk, Dong In Kim, and Kyung Sup Kwak

Utility-Based Wireless Resource Albcation tor Variable Rate Transmission.

Xiaolu Zhang, Meixia Tro, and Chun Sum Ng

Asymptotic Ergodic Capacity of Mritidimensional Vector-Sensor Array MMO Chamels..................3297

Ozgur Enzug

Highly Accurate Closed-Form Approximations to the Sum of $\alpha$ - 4 Variates and Applications

Daniei Benevides da Cosu, Michel Daoud Yacoub, and Jose Candido Silveira Sanios Fiho

An Improved Deterministic SoS Chamel Simulator for Multiple Uncorrelated Rayleigh Fading Channels. ...

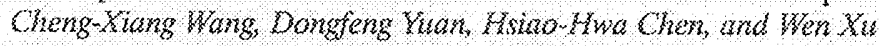

Transmitter Optimization for Correlated MSO Fading Channels with Generic Mean and Covariance Feebback.........3312 Jum

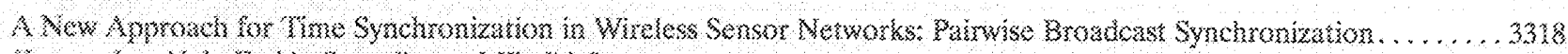

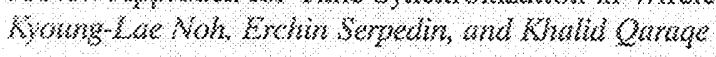

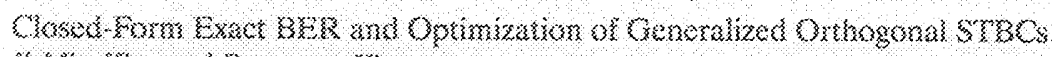

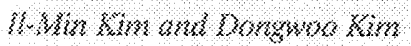

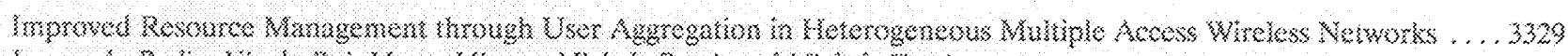

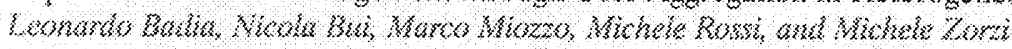

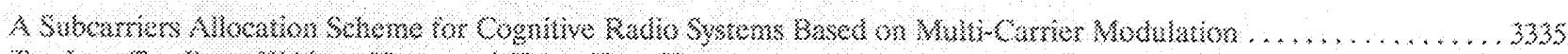

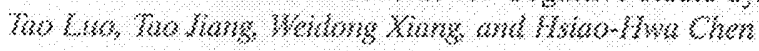

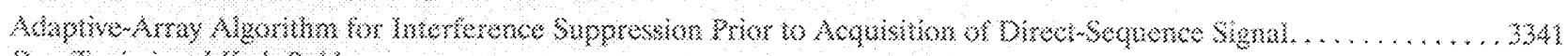

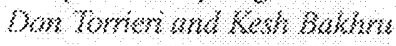

\section{TransachoNs PapkRs}

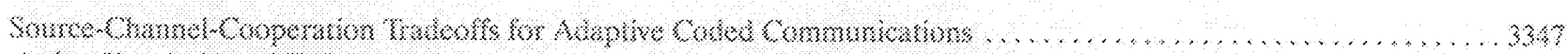

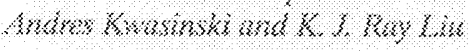

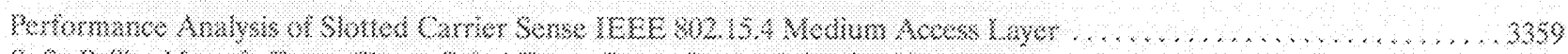

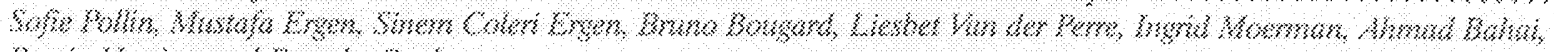

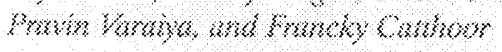

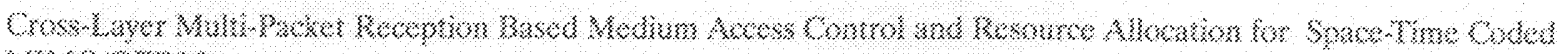

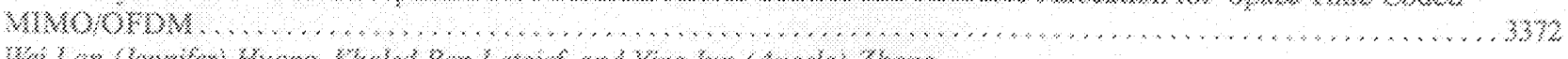

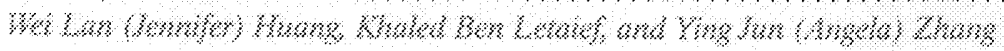

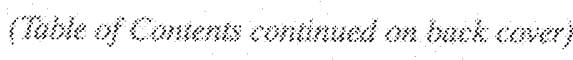

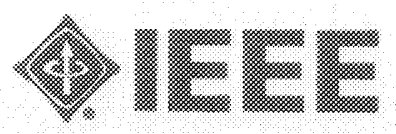

